\title{
Review Article \\ Redox Regulation of Inflammatory Processes Is Enzymatically Controlled
}

\author{
Inken Lorenzen, ${ }^{1}$ Lisa Mullen, ${ }^{2}$ Sander Bekeschus, ${ }^{3}$ and Eva-Maria Hanschmann ${ }^{4}$ \\ ${ }^{1}$ Department of Structural Biology, Institute of Zoology, Kiel University, Kiel, Germany \\ ${ }^{2}$ Brighton and Sussex Medical School, Falmer, Brighton, UK \\ ${ }^{3}$ Leibniz-Institute for Plasma Science and Technology (INP Greifswald), ZIK plasmatis, Greifswald, Germany \\ ${ }^{4}$ Department of Neurology, Medical Faculty, Heinrich-Heine University, Düsseldorf, Germany
}

Correspondence should be addressed to Eva-Maria Hanschmann; eva-maria.hanschmann@med.uni-duesseldorf.de

Received 3 March 2017; Revised 6 July 2017; Accepted 25 July 2017; Published 8 October 2017

Academic Editor: Shane Thomas

Copyright ( 2017 Inken Lorenzen et al. This is an open access article distributed under the Creative Commons Attribution License, which permits unrestricted use, distribution, and reproduction in any medium, provided the original work is properly cited.

\begin{abstract}
Redox regulation depends on the enzymatically controlled production and decay of redox active molecules. NADPH oxidases, superoxide dismutases, nitric oxide synthases, and others produce the redox active molecules superoxide, hydrogen peroxide, nitric oxide, and hydrogen sulfide. These react with target proteins inducing spatiotemporal modifications of cysteine residues within different signaling cascades. Thioredoxin family proteins are key regulators of the redox state of proteins. They regulate the formation and removal of oxidative modifications by specific thiol reduction and oxidation. All of these redox enzymes affect inflammatory processes and the innate and adaptive immune response. Interestingly, this regulation involves different mechanisms in different biological compartments and specialized cell types. The localization and activity of distinct proteins including, for instance, the transcription factor $\mathrm{NF} \kappa \mathrm{B}$ and the immune mediator HMGB1 are redox-regulated. The transmembrane protein ADAM17 releases proinflammatory mediators, such as TNF $\alpha$, and is itself regulated by a thiol switch. Moreover, extracellular redox enzymes were shown to modulate the activity and migration behavior of various types of immune cells by acting as cytokines and/or chemokines. Within this review article, we will address the concept of redox signaling and the functions of both redox enzymes and redox active molecules in innate and adaptive immune responses.
\end{abstract}

\section{Concept of Redox Signaling}

Cells can receive and respond to distinct signals and environmental changes; they can send out signals in order to communicate with other cells. Signal transduction can depend on intracellular or membrane-bound receptors that have the ability to bind specific ligands that induce particular signaling cascades involving second messengers and rapid, reversible posttranslational modifications of transducer and effector proteins. Some signaling molecules can pass the plasma membrane and directly interact with specific targets. In the case of redox regulation, we can distinguish between different spatiotemporal modifications of cysteine residues, such as the formation of inter- or intramolecular disulfide bridges, S-glutathionylation by the formation of a mixed disulfide with glutathione (GSH), S-nitrosylation in the presence of nitric oxide (NO), the formation of sulfenic acid, for example, in the presence of hydrogen peroxide $\left(\mathrm{H}_{2} \mathrm{O}_{2}\right)$, or the formation of S-sulfhydration by hydrogen sulfide $\left(\mathrm{H}_{2} \mathrm{~S}\right)$. All these modifications modify the redox state of a particular thiol group and can affect a protein in terms of structure, localization, and/or activity [1] (Figure 1). These regulatory thiol groups are known as thiol switches [2]. Interestingly, redox modifications also affect other posttranslational modifications, essential for signal transduction, for instance, phosphorylation. Redox signaling occurs upon specific stimuli and is localized in specific compartments or confined areas within a cellular compartment. The signal is sensed by a particular receptor, inducing the production and release of second messengers such as $\mathrm{H}_{2} \mathrm{O}_{2}, \mathrm{NO}$, and $\mathrm{H}_{2} \mathrm{~S}$. Interestingly, not all reactive oxygen, nitrogen, and sulfur species are considered signaling molecules. This is due to their high reactivity towards a wide range of unspecific targets including various biomolecules, such as DNA, lipids, and proteins, and the lack 


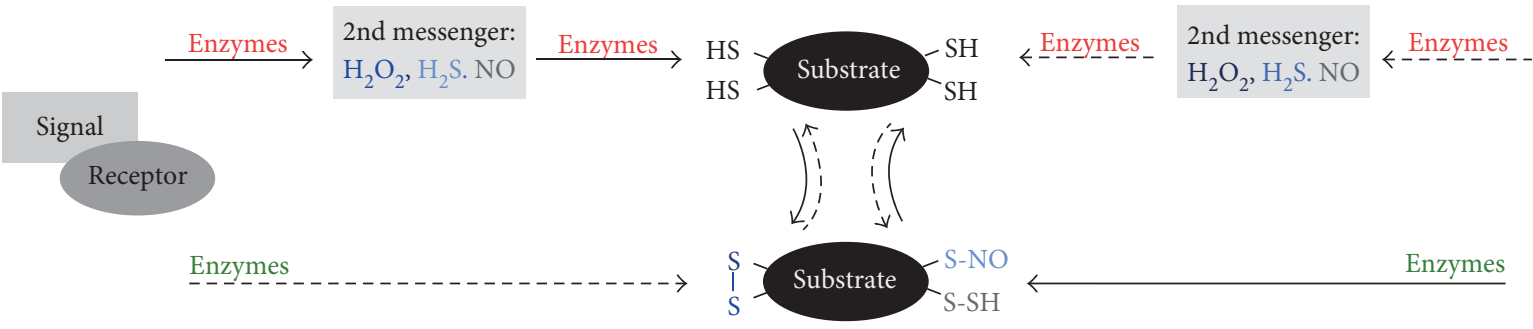

Figure 1: Concept of redox signaling. A signal is sensed by its receptor, inducing the enzymatic catalyzed production and release of second messengers (e.g., $\mathrm{H}_{2} \mathrm{O}_{2}$, NO, and $\mathrm{H}_{2} \mathrm{~S}$ ). These activate a cascade of transducing proteins via specific oxidative modifications at Cys residues (e.g., disulfide formation, nitrosylation, and sulfhydration). The effector molecule induces the biological response. A signal can also induce the reduction of distinct Cys residues. The activated signaling cascade becomes terminated, and cysteinyl modifications are reversed. The involved thiol groups are known as thiol switches. Their reduction (green), as well as their oxidation (red) are regulated by different enzymes.

of regulation of their production and decay. The hydroxyl radical, for instance, is nonenzymatically produced in the Fenton reaction and reacts with basically any molecule due to its high reactivity and lack of specificity [1]. Similarly, peroxynitrite is not considered a second messenger, because it is spontaneously formed by the reaction of nitric oxide with superoxide and a strong oxidizing agent with a secondorder rate constant of $10^{10} \mathrm{M}^{-1} \cdot \mathrm{s}^{-1}$ that also oxidizes various biomolecules (reviewed in $[3,4]$ ). $\mathrm{H}_{2} \mathrm{O}_{2}, \mathrm{NO}$, and $\mathrm{H}_{2} \mathrm{~S}$ activate effector molecules that induce a certain biological response via specific transducing molecules including redox couples, for example, GSH and oxidized glutathione (GSSG) and enzymes, for example, oxidoreductases of the thioredoxin (Trx) family. In the absence of the signal, the activated signaling cascade becomes terminated and cysteinyl modifications are reversed. These thiol switches have been predicted to play a role in almost every signaling cascade and are therefore essential for all biological processes. Obviously, physiological redox signaling is highly regulated and depends on the controlled oxidation as well as the specific reduction of substrates $[1,5]$. The dysregulation or even disruption of redox signaling has been described as oxidative stress, a hallmark of various pathologies [6].

As mentioned above, the production and release of redox active molecules are regulated by enzymes that are located in various cellular compartments and also in the extracellular space (Figure 2). Complexes I and III of the respiratory chain and enzymes such as nicotinamide adenine dinucleotide phosphate- (NADPH-) oxidases (NOX) and xanthine oxidase produce superoxide $\left(\mathrm{O}_{2}^{\bullet-}\right)$. Superoxide dismutases (SOD) convert $\mathrm{O}_{2}^{\bullet-}$ into $\mathrm{H}_{2} \mathrm{O}_{2}$. Different peroxidases, including catalase and the Trx family members peroxiredoxins (Prxs) and glutathione peroxidases $(\mathrm{Gpx})$, reduce $\mathrm{H}_{2} \mathrm{O}_{2}$ to water. $\mathrm{NO}$ is synthesized by one of the three isoforms of nitric oxide synthase (NOS), that is, neuronal nNOS, inducible iNOS, and endothelial eNOS. $\mathrm{H}_{2} \mathrm{~S}$ is produced by cystathionine $\beta$-synthase, cystathionine $\gamma$-lyase, L-cysteine desulfhydrase, and 3-mercaptopyruvate sulfurtransferase (for an overview see [1] and references within). In addition to the production, the degradation of these molecules is also enzymatically regulated (Figure 2). Contrary to previous understanding, free oxygen and nitrogen species cannot generally oxidize thiol groups directly. The reaction rate of $\mathrm{H}_{2} \mathrm{O}_{2}$ with the highly abundant peroxidases of the Trx family, Prxs, ranges from $10^{6}$ to $10^{8} \mathrm{M}^{-1} \cdot \mathrm{s}^{-1}$. The reaction rate of other reactive protein thiols and free Cys is significantly lower in a range of approximately $10^{1} \mathrm{M}^{-1} \cdot \mathrm{s}^{-1}[7,8]$. Due to high protein expression and reactivity, a molecule of $\mathrm{H}_{2} \mathrm{O}_{2}$ is more prone to oxidize a Prx molecule than the thiol group of any other protein. Prxs are peroxidases that can function in cellular signaling as peroxide sensors. Moreover, $\mathrm{H}_{2} \mathrm{O}_{2}$ signaling can be conducted via GPxs and GSH [9]. Trx family proteins are key regulators of redox signaling by regulating the redox state of particular substrate proteins. They catalyze disulfide reduction and isomerisation reactions and regulate deglutathionylation, as well as denitrosylation and depersulfidation. Moreover, they are also involved in the oxidation of thiols, for example, by catalyzing S-glutathionylation, transnitrosylation, and S-sulfhydration. Trx proteins contain the structural Trx fold and an active site motif that contains one or two cysteinyl residues and is essential for the catalytic monothiol and dithiol mechanisms. Substrates of Trx family proteins include enzymes such as ribonucleotide reductase [10, 11] Sirtuin-1 [12], caspase-3 [13], the mitogen-activated protein (MAP) kinase apoptosis signalregulating kinase 1 (ASK1) [14] and mercaptopyruvate sulfur transferase (MST) [15], transcription factors such as nuclear factor kappa B $(\mathrm{NF} \kappa \mathrm{B})$ [16], and signal transducer and activator of transcription 3 (STAT3) [17]. Moreover, components of the Wnt signaling pathway (dishevelled [18]), cytoskeletal dynamics (e.g., collapsin response mediator protein $2[19,20]$ ), and innate immunity (e.g., myeloid differentiation primary response 88 (Myd88) [21] and a disintegrin and metalloproteinase 17 (ADAM17) [22]) are regulated by Trx proteins. So far, not much is known about the specificity of substrate recognition. However, it is known that not every surface-exposed Cys residue is involved in redox regulation. Lillig and Berndt have shown that the reactivity of a cysteinyl residue depends on the surrounding amino acids creating the electrostatic and hydrophobic environment of the thiol group [23]. Recently, it was demonstrated that substrate recognition depends on kinetic constraints, complementary molecular geometries, and the electrostatic surface potential of the oxidoreductase and the target protein $[8,24]$. 


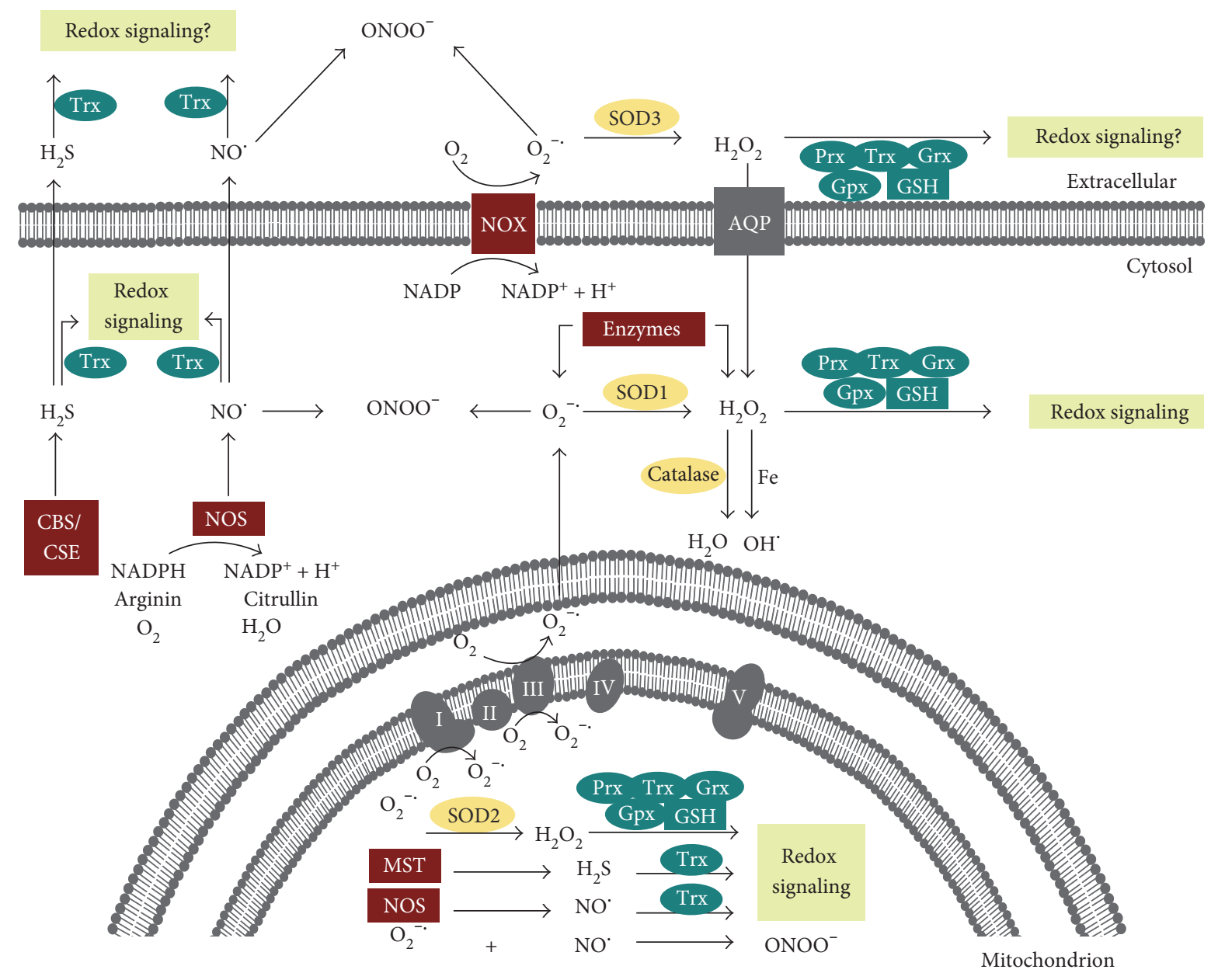

FIgURE 2: Redox regulation is enzymatically controlled. Illustration of cellular and extracellular enzymes that (i) generate redox active species (red), (ii) decompose reactive species, and are classified as antioxidants (yellow) or (iii) participate in redox signaling (blue). In the cytosol, superoxide $\left(\mathrm{O}_{2}^{-}\right)$and hydrogen peroxide $\left(\mathrm{H}_{2} \mathrm{O}_{2}\right)$ can be produced by specific enzymes; the cytosolic SOD1 can convert $\mathrm{O}_{2}^{-}$to $\mathrm{H}_{2} \mathrm{O}_{2}$. Moreover, the NADPH and oxygen-dependent membrane protein NADPH-oxidase (NOX) can produce $\mathrm{O}_{2}^{-}$that is converted to $\mathrm{H}_{2} \mathrm{O}_{2}$ by extracellular SOD3. The latter can cross the membrane via simple diffusion and aquaporins. $\mathrm{H}_{2} \mathrm{O}_{2}$ can participate in cell signaling as a second messenger via the action of the thioredoxin family members peroxiredoxin (Prx), thioredoxin (Trx), glutaredoxin (Grx), and glutathione peroxidases. These enzymes are NADPH- and mostly glutathione- (GSH-) dependent. $\mathrm{H}_{2} \mathrm{O}_{2}$ can also be reduced to water by the peroxidase catalase, which is mainly located in peroxisomes. However, in the presence of free iron, the highly reactive and damaging hydroxyl radical $\left(\mathrm{OH}^{\bullet}\right)$ is formed from $\mathrm{H}_{2} \mathrm{O}_{2}$ via the Fenton reaction. Nitric oxide (NO) is generated by cytosolic NO-synthase (NOS) and hydrogen sulfite $\left(\mathrm{H}_{2} \mathrm{~S}\right)$ by the enzymes cystathionine $\beta$-synthase (CBS) and cystathionine $\gamma$-lyase (CSE). Both constitute second messengers that can participate in redox signaling via the action of Trx. Note that peroxynitrite $\left(\mathrm{ONOO}^{-}\right)$can spontaneously form in the presence of $\mathrm{O}_{2}^{-}$and $\mathrm{NO}$, inducing irreversible modifications of various biomolecules and thus not participating in redox signaling. In mitochondria, complexes I and III of the mitochondrial respiratory chain produce superoxide $\left(\mathrm{O}_{2}^{-\bullet}\right)$. Superoxide dismutase 2 (SOD2) converts $\mathrm{O}_{2}^{-}$to $\mathrm{H}_{2} \mathrm{O}_{2}$. Mitochondrial $\mathrm{NOS}$ and 3-mercaptopyruvate sulfurtransferase (MST) produce $\mathrm{NO}$ and $\mathrm{H}_{2} \mathrm{~S}$, respectively. Mitochondrial $\mathrm{H}_{2} \mathrm{O}_{2}, \mathrm{NO}$, and $\mathrm{H}_{2} \mathrm{~S}$ can participate in redox signaling. Similar to the cytosol, $\mathrm{ONOO}^{-}$and $\mathrm{OH}^{\bullet}$ can also be formed in the mitochondria. In the extracellular environment, NOX and SOD3 produce $\mathrm{O}_{2}^{-}$and $\mathrm{H}_{2} \mathrm{O}_{2}$ and the intracellularly produced $\mathrm{NO}$ and $\mathrm{H}_{2} \mathrm{~S}$ can cross the plasma membrane. Members of the Trx family of proteins are found extracellular. Therefore, the intracellular concept of redox signaling might also occur in the microenvironment of the cell.

\section{Redox Regulation of the Inflammatory Response}

Upon tissue damage and infection, the inflammatory response is induced. This highly regulated and protective process facilitates the removal of foreign and/or damaged components, as well as tissue repair and is terminated when a return to physiological conditions is achieved. The inflammatory response is composed of distinct receptor proteins, inflammatory mediators, and specialized cell types, as well as changes in tissue homeostasis and blood flow. Initiation of inflammation is reliant on the production of a number of cytokines which are produced by activated cells of the innate immune system in response to a range of stimuli. Proinflammatory cytokines are essential for the activation of the adaptive immunity, that is, B- and T-lymphocytes. In some circumstances, the production of these proinflammatory cytokines is maintained beyond that required to facilitate 
microbial destruction and tissue repair, resulting in a chronic inflammatory response where both innate and adaptive immune cells are chronically activated, inducing tissue damage and subsequent autoimmune disease. Even though the exact redox signaling cascades are not fully understood, it is well known that the production of reactive oxygen species (ROS) and reactive nitrogen species (RNS) is essential for the onset, progression, and also the termination of inflammatory processes. Redox-regulated processes involve the innate, as well as the adaptive immunity, for example, the oxidative burst of immune cells and pathogen killing, cellular signal transduction, and regulation of gene transcription, cytokine release, and antigen presentation as well as the regulation of the activation, differentiation, and migration of immune cells and wound healing [1, 25-27]. Particularly, not only NO and $\mathrm{H}_{2} \mathrm{O}_{2}$ are essential during inflammation but also $\mathrm{H}_{2} \mathrm{~S}$ has been shown to possess anti- and proinflammatory functions $[28,29]$. Production of $\mathrm{NO}$ as a signaling molecule with microbicidal, antiviral, and antiparasital as well as immunomodulatory functions is essential for inflammatory processes (reviewed in $[30,31])$. NO constitutes an important second messenger in the inflammatory response with various functions in the classical activation during the onset of the inflammation, signal transduction, revascularisation, and tissue repair [32].

Reactive species are produced by phagocytic cells of the innate immune system, such as monocytes, macrophages, neutrophils, and dendritic cells, during the oxidative burst in order to kill pathogens as well as during tissue repair [33, 34]. Myeloperoxidase (MPO) catalyzes the reaction of $\mathrm{H}_{2} \mathrm{O}_{2}$ to highly oxidizing and microbicidal hypochlorous acid $(\mathrm{HOCl})$ and hypobromous acid. This reaction can also be catalyzed by the eosinophil peroxidase. Another bactericidal and fungicidal enzyme that acts in the innate immune defence is the heme protein lactoperoxidase (LPO) generating hypothiocyanite ( $\left.{ }^{-} \mathrm{OSCN}\right)$ from thiocyanate $\left(\mathrm{SCN}^{-}\right)$ and $\mathrm{H}_{2} \mathrm{O}_{2}$. The latter is a downstream metabolite of superoxide that is enzymatically produced by the NOX enzymes Duox1 and particularly Duox2 [35, 36]. In addition, NO and further RNS have been shown to be present in the phagosome and participate in eradication of pathogens [32]. Activation of NOX and the oxidative burst occurs only upon full activation of neutrophils in the presence of pathogens. Their antimicrobial activity can be primed by inflammatory cytokines, chemokines, anaphylatoxins, or pathogenassociated molecular pattern (PAMPs), for example, compounds of bacterial cell walls such as lipopolysaccharides (LPS) and lipoteichoic acid, flagellin, and bacterial DNA that are recognized by pathogen recognition receptors such as Toll-like receptors (TLRs) and cytoplasmic NOD-like receptors (NLRs) [37]. The latter are also part of the inflammasome that facilitates the cytosolic, caspase-1-mediated maturation of inflammatory cytokines and that has been shown to be redox-regulated [38], (reviewed in [26]). Both, NLRs and TLRs also recognize endogenous damageassociated molecular patterns (DAMPs), such as the redoxregulated high mobility group protein 1 (HMGB1) or metabolites like ATP, which are also known as danger signals [39]. TLRs are not exclusively expressed in phagocytic cells and are present in the first barriers of defence, such as the skin, airway, blood vessels, and colon. TLRs are involved in ROS production. Interestingly, LPS-activated neutrophils produce $\mathrm{H}_{2} \mathrm{O}_{2}$ that induces the TLR2 expression in endothelial cells promoting the immune defence via redox-regulated signaling events [40]. The cytosolic Toll/IL-1 receptor (TIR) domain of TLRs associates with the signal transduction adaptor protein Myd88 that recruits and activates a set of proteins, inducing downstream Map kinases (e.g., JNK and p38) and the phosphorylation and degradation of $\mathrm{I} \kappa \mathrm{B}, \mathrm{NF} \kappa \mathrm{B}$ activation, and expression of target genes (Figure 3) [41]. Various components of this pathway are susceptible to redox regulation and were shown to interact with Trx family proteins, including $\mathrm{NF} \kappa \mathrm{B}$, the transcription factor that controls, for example, the expression of proinflammatory cytokines, chemokines, growth factors, prostaglandins, adhesion molecules, and NOX2 as well as iNOS and also nNOS $[1,42,43]$, promoting leukocyte recruitment and activation of the surrounding tissue. Interestingly, cytokines can be expressed as cytosolic or membrane-bound "precursors" and are activated and released by redox-regulated, proteolytical cleavage via cytosolic multiprotein complexes called inflammasomes or specific proteases such as ADAM17 [26, 44-47]. Cytokines are not the only proteins that are secreted upon inflammation. A large number of proteins secreted from innate immune cells in response to inflammatory stimuli have been shown to be glutathionylated [48]. Recent studies have seen the refinement of redox proteomic techniques to interrogate those proteins, identifying a substantial number of glutathionylated proteins, both intracellular and secreted [49, 50]. Among the secreted proteins, Trx1, Trx80, Prx1, and Prx2 were detected that have cytokine and/or chemokine-like functions [1, 51]. Secreted, glutathionylated Prx2 was recently described to function as danger signal [52]. And also, the related macrophage-inhibitory factor (MIF-1) has immunomodulatory functions [1].

Redox regulation of inflammation and of immune responses is not restricted to the activation and subsequent activity of innate immune cells. Generation of both humoral and cell-mediated adaptive immunity depends on activation of T helper cells, a process heavily reliant on the redox potential of the microenvironment of these cells $[53,54]$. A reducing environment is necessary for both optimal activation of T-cells $[55,56]$ and for the downstream proliferation of these cells $[57,58]$ that is essential for generating an adaptive immune response. As these effector $\mathrm{CD} 4^{+} \mathrm{T}$-cells are essential for inducing full activation and class switching in activated $\mathrm{B}$ lymphocytes, the effects of changes in the redox environment also extend to the humoral arm of the adaptive immune response. It is perhaps unsurprising that redox changes in antigen-presenting cells can also help to determine whether T-cells develop into Th1 or Th2 cells $[59,60]$ given the importance of the interactions between $\mathrm{T}$-cells and their antigen-presenting cells in T-cell activation. Increases in cellular ROS levels have been shown to be essential, for example, during T-cell activation, antigen presentation, and receptor-mediated cell signaling. Interestingly, administration of antioxidants such as the seleno-compound ebselen inhibits and impairs these functions [1, 61]. This 


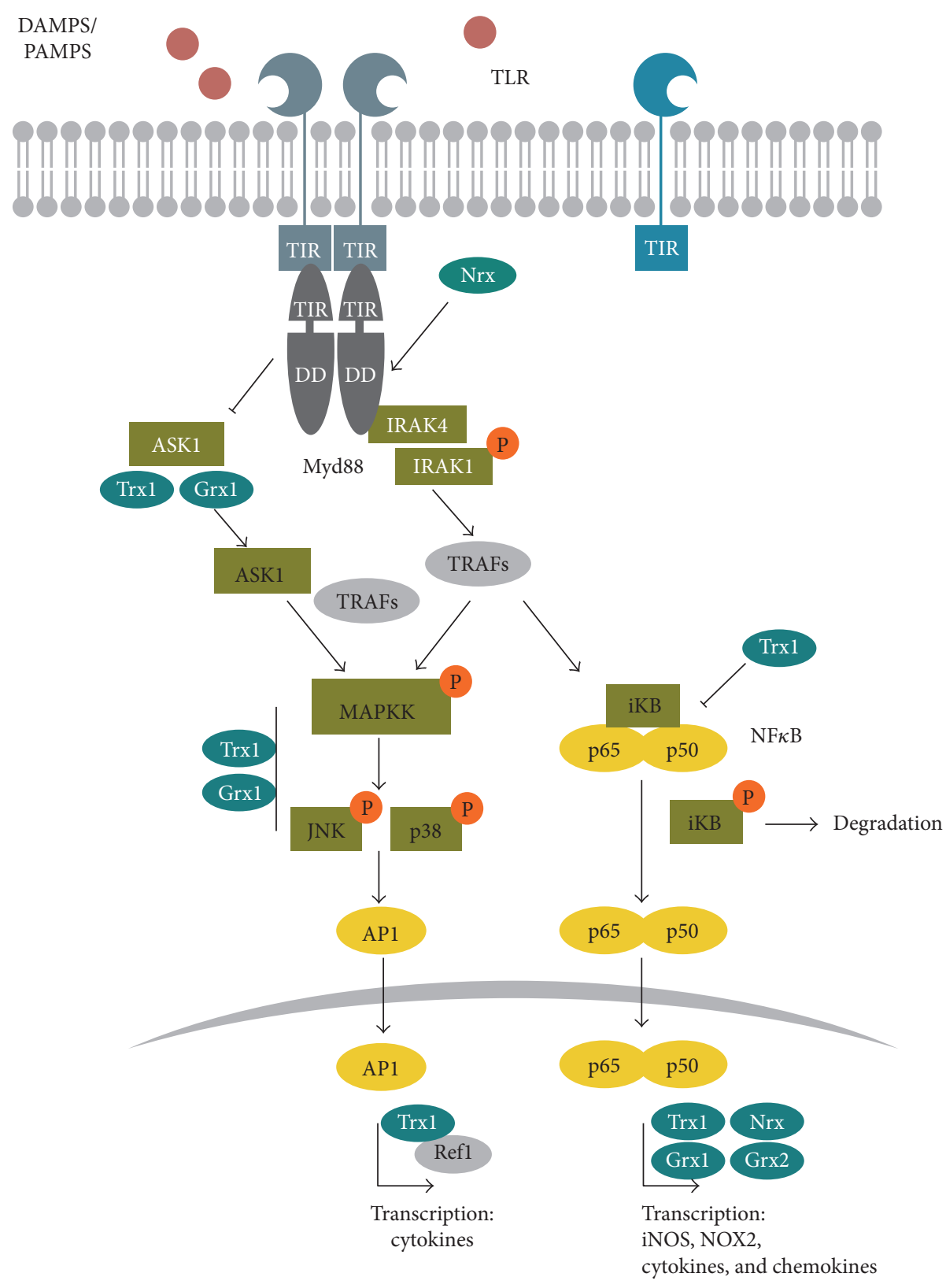

FIGURE 3: TLR signaling is redox-regulated. The general concept of the TLR signaling is illustrated, emphasizing the redox-regulated steps and molecules; note that this illustration is simplified and that specific TLR pathways include different proteins. PAMPs and DAMPs are recognized by their specific TLR, which can lead to homo- and heterodimerisation. Upon ligand binding, the TLR associates with the adaptor protein Myd88, which is sensitive to oxidation by hydrogen peroxide and can be regulated by Nrx. Myd88 recruits IRAK4 that phosphorylates IRAK1, which in turn activates additional proteins (e.g., TRAFs and IKK, not shown). MAP kinases and NF $\kappa$ B are activated. MAP kinase signaling is regulated by Trx1 and Grx1 and eventually activates the transcription factor AP1, which has two Cys residues in its DNA binding domain that are reduced by Trx 1 via Ref1. The NF $\kappa \mathrm{B}$ subunits p50 and p60 are kept in an inhibitory i $\kappa \mathrm{B} /$ NF $\kappa$ B-complex in the cytosol. Reduced Trxl inhibits the dissociation of this complex. Upon dissociation, i $\kappa \mathrm{B}$ is phosphorylated and degraded by the proteasome. NF- $\kappa \mathrm{B}$ translocates into the nucleus, where it binds to the DNA, a process that depends on the reduction of Cys62 and is regulated by Trx1, Grx1, and/or Nrx. An additional redox-regulated pathway involving ASK1 exists in TLR4 signaling. ASK1 is kept in an inactive complex by reduced Trx1. Upon TLR activation, Trx1 is oxidized, the complex dissociates and active ASK1 regulates JNK activity via different proteins including TRAFs.

may help to explain observations that autoimmune diseases such as rheumatoid arthritis [62] and multiple sclerosis [63] are associated with increased levels of oxidative stress. Like many autoimmune diseases and chronic inflammatory diseases, it is still unclear whether oxidative stress is a cause or effect of these conditions. However, for these particular conditions, treatment with antioxidants does actually ameliorate disease, at least in animal models [64], suggesting that oxidative stress does indeed play a role. Furthermore, one of the frontline treatments for people with multiple sclerosis, 
TABLE 1: Thiol switches in inflammatory signaling processes.

\begin{tabular}{|c|c|c|c|c|}
\hline Protein & Thiol/modification & Function & Regulation & Reference \\
\hline ADAM17 & $\begin{array}{l}\mathrm{C}_{600}, \mathrm{C}_{630}, \mathrm{C}_{635}, \mathrm{C}_{640}: \\
\text { intermolecular disulfides }\end{array}$ & $\begin{array}{l}\text { Linear order of disulfides } \\
\left(\mathrm{C}_{600-630} ; \mathrm{C}_{635-640}\right): \text { open, } \\
\text { flexible structure } \\
\text { Overlaying disulfides } \\
\left(\mathrm{C}_{600-635} ; \mathrm{C}_{630-640}\right): \text { abrogates } \\
\text { membrane binding and } \\
\text { substrate recognition }\end{array}$ & $\begin{array}{l}\text { PDI catalyzes the isomerisation } \\
\text { from the linear to the overlaying } \\
\text { disulfide pattern. }\end{array}$ & {$[135,141]$} \\
\hline Ask1 & $\begin{array}{l}\mathrm{C}_{200,250}: \text { intramolecular } \\
\text { disulfide } \\
\mathrm{C}_{250}: \text { interaction with Trx1 }\end{array}$ & $\begin{array}{l}\text { ASK1 is involved in TLR4 } \\
\text { signaling and is involved in } \\
\text { TNF } \alpha \text {-induced apoptosis. } \\
\text { Intramolecular disulfide induces } \\
\text { conformational changes within } \\
\text { the Trx-binding region. }\end{array}$ & $\begin{array}{l}\text { Trx1 and Grx1 bind to ASK1 } \\
\text { and inhibit the kinase; in case } \\
\text { of Trx1 proteasomal degradation } \\
\text { is induced. Oxidation of } \\
\text { Trx1/ Grx1 induces the dissociation } \\
\text { of the complex and kinase activation. }\end{array}$ & {$[14,96,97,257]$} \\
\hline EGFR & $\mathrm{C}_{797}:$ sulfenylation & $\begin{array}{l}\text { EGFR-mediated signaling; } \\
\text { sulfenylation enhances tyrosine } \\
\text { kinase activity. }\end{array}$ & Oxidation by $\mathrm{H}_{2} \mathrm{O}_{2}$ & {$[90,91]$} \\
\hline HMGB1 & $\begin{array}{l}\mathrm{C}_{23}, \mathrm{C}_{45}, \mathrm{C}_{106}: \\
\text { intramolecular disulfide } \\
\left(\mathrm{C}_{23-45}\right) \text {, } \\
\text { sulfenylation }\left(\mathrm{C}_{106}\right)\end{array}$ & $\begin{array}{l}\text { Fully reduced: chemotactic } \\
\text { activity; intramolecular disulfide } \\
\left(\mathrm{C}_{23-45}\right) \text {, reduced } \mathrm{C}_{106}: \text { cytokine }\end{array}$ & Trx1 (Grx1?) & {$[154,155,157]$} \\
\hline Myd88 & $\begin{array}{l}8 \text { Cys residues: } \\
\text { (i) intermolecular disulfides } \\
\text { (ii) nitrosylation }\end{array}$ & $\begin{array}{c}\text { Intermolecular disulfides: } \\
\text { oligomerisation during } \\
\text { TLR signaling } \\
\end{array}$ & $\begin{array}{c}\text { Oxidation by } \mathrm{H}_{2} \mathrm{O}_{2} \text { (Prx?), } \\
\text { Nrx, Trx }\end{array}$ & {$[21,93,94]$} \\
\hline $\mathrm{NF} \kappa \mathrm{B}$ & $\begin{array}{l}\mathrm{C}_{62} \text { : } \\
\text { (i) glutathionylation } \\
\text { (ii) sulfenylation }\end{array}$ & $\begin{array}{c}\text { Reduced } \mathrm{C}_{62}: \text { DNA } \\
\text { binding and gene expression }\end{array}$ & $\begin{array}{l}\text { Bound in an inactive complex } \\
\text { by Trx1 (cytosol), reduction by } \\
\text { Trx1, Grx1 (nucleus) }\end{array}$ & {$[16,99,101]$} \\
\hline Src & $\begin{array}{l}\mathrm{C}_{245}, \mathrm{C}_{487}: \\
\text { disulfide formation }\end{array}$ & $\begin{array}{l}\text { Intramolecular disulfide connects } \\
\mathrm{SH} 2 \text { and kinase domain and stabilizes } \\
\text { the active conformation of the kinase }\end{array}$ & Oxidation by $\mathrm{H}_{2} \mathrm{O}_{2}$ & {$[88,89]$} \\
\hline
\end{tabular}

dimethyl fumarate, exerts its therapeutic effects by upregulating antioxidant enzyme synthesis [65]. One possible mechanism by which oxidative stress could impact these conditions is via effects on T-cells that infiltrate the sites of disease, a recognized phenomenon in these pathologies [66]. If these cells then encounter relatively oxidizing conditions, this could influence their activation into the more inflammatory phenotypes such as Th1 and Th17 phenotypes, thereby exacerbating disease. Indeed, it has been suggested that exposure of T-cells to increased oxidative stress in rheumatoid arthritis causes them to become refractory to apoptosis leading to a perpetual immune response [67].

Within the next chapter, we will introduce distinct thiol switches and their impact on cell signaling and inflammatory processes (Table 1).

\section{Thiol Switches in the Inflammatory Response}

3.1. TLR Signaling. In terms of redox signaling, the production of the second messenger $\mathrm{H}_{2} \mathrm{O}_{2}$ is closely linked to the transmembrane multidomain NOX complexes. These transport electrons via NADPH, flavin-adenine dinucleotide (FAD), and heme from the cytoplasmic side of the plasma membrane to the extracellular part, where they are transferred to oxygen. By the action of extracellular SOD3, the produced superoxide is converted to $\mathrm{H}_{2} \mathrm{O}_{2}$, which passes the membrane by diffusion or via aquaporins (Figure 2). Superoxide $/ \mathrm{H}_{2} \mathrm{O}_{2}$ production occurs in close proximity to the receptor complex, potentially in specific signaling platforms within lipid rafts, caveolae, or endosomes [68]. The NOX family comprises seven members, NOX1 to NOX5 and Duox1 and Duox2. The structure and regulation of the different NOXs have been extensively reviewed previously [69-72]. NOX-dependent ROS production can depend on endocytosis of activated receptor NOX complexes in redoxactive endosomes, the redoxosomes. The formation of redoxosomes occurs out of lipid rafts, which contain inactive NOX as well as ligand-bound receptors that initiate NOX activity and require activated Rac1. Inhibition of endocytosis and formation of redoxosomes reduces superoxide formation and downstream activation of $\mathrm{NF} \kappa \mathrm{B}$. For proper signaling, SOD activity and chloride channels are required, which are believed to export superoxide into the cytoplasm and import protons that stabilize the $\mathrm{pH}$ within the redoxosomes (reviewed in $[73,74]$ ). Interestingly, this was demonstrated for IL- $1 \beta$ - and TNF $\alpha$-induced signaling, but not for thrombin-activated NOX1 [74-77]. NOX1 is expressed in the colon and the vascular system and can be triggered by flagellin, via TLR5 [78], by LPS via TLR4 [79], and by CpG oligonucleotides via TLR9 [80] and is sensitive to IFN $\gamma$ 
[81]. NOX2 constitutes the first identified NOX, which is highly expressed in phagocytic active neutrophils and macrophages and to a much lower rate in dendritic cells [82]. NOX2 is sensitive to multiple TLRs [83] and essential for the oxidative burst. The assembly and activation of NOX2 occur upon fully activation of neutrophils in the presence of pathogens. Dendritic cells are specialized for antigen presentation, and NOX2 is needed for proper antigen presentation towards T-cells $[84,85]$. In the airway epithelium, Duoxl was shown to depend on TLR4 [86]; regulating the expression of chemokines, which attract neutrophils and macrophages $[83,86,87]$. The physical interaction between the TIR domain of TLR4 and the cytoplasmic tail of NOX4 results in an activation of src, which phosphorylates $\operatorname{IkB} \alpha$, thereby activating $\mathrm{NF} \kappa \mathrm{B}$ and target genes [87]. The activity of src is regulated by tyrosine phosphorylation and can be boosted by a thiol switch [88]. Protein tyrosine phosphatases (PTPs) remove an inhibitory phosphorylation of a Cterminal Y527 residue and thus its inhibitory interaction with the SH2 domain of the kinase, followed by autophosphorylation. This active conformation of the protein is stabilized by a reversible thiol switch. C245 and C487 are oxidized and form a disulfide bond connecting the $\mathrm{SH} 2$ and the kinase domain. An exchange of these cysteinyl residues to alanine residues results in a redox unresponsive variant $[88,89]$. Interestingly, src is not only involved in the regulation of NOX signaling but also targets the epidermal growth factor receptor (EGFR) that was also shown to undergo thiol oxidation. The targeted cysteine residue is located close to the ATP-binding site within the cytoplasmic part of the receptor protein (Figure 4). An exchange of the cysteine residue to a serine residue induces a 2.5 -fold increase in the ATPase activity of EGFR [90, 91]. Besides src and EGFR, PTPs, for example, PTP1B, are targets for redox modification, that is, reversible oxidation of the catalytic active cysteine that renders the protein inactive $[91,92]$. All three proteins are targeted by $\mathrm{H}_{2} \mathrm{O}_{2}$, produced by Duoxl in response to extracellular ATP, which functions as danger signal in the airway epithelium host defence [91]. These three examples show how specific and diverse redox regulation can occur during the same conditions and stimuli within a signaling cascade. Even though all transducers are oxidized at one or two particular Cys residues, the effect on the protein activity differs from being turned on or off like a redox switch to being modulated! Even though the oxidation has been shown, the exact regulatory mechanisms are still mostly elusive. It is however tempting to speculate that the oxidation by hydrogen peroxide is mediated via cytosolic Prxs and the reduction via, for example, Trx. Trx proteins have been already shown to regulate Myd88 and downstream Map kinases. Most TLRs need the adaptor protein Myd88 for signal transduction, which functions downstream of the signal-receptor complex upon ligand binding. Myd88 oligomerizes with the interleukin-1 receptor-associated kinase (IRAK) forming a signal initiation complex. The complex signal transduction involves various proteins and kinases, eventually triggering MAP kinases and $\mathrm{NF} \kappa \mathrm{B}$ signaling pathways (Figure 3) [41]. Recently, Stottmeier and Dick demonstrated that Myd88 undergoes redox regulation. In the presence of $\mathrm{H}_{2} \mathrm{O}_{2}$, Myd88 dimerizes and forms disulfide-linked conjugates with other proteins via eight conserved Cys residues (Figure 4). Interestingly, the oxidation by hydrogen peroxide is comparably sensitive to oxidation of Prx2 [93]. S-Nitrosylation of distinct Cys residues of Myd88 has also been described [94]. Nucleoredoxin (Nrx) controls TLR4 signaling by regulation of Myd88, that is, by stabilizing the interaction of Myd88 with flightless homolog 1 [21]. Moreover, Nrx was shown to regulate the adaptor protein, potentially as a disulfide reductase. Nrx is related with Trx, which additionally catalyzes de- and transnitrosylation of proteins. It is tempting to speculate that Nrx has similar catalytic mechanisms and that it could regulate Myd88 activity not only as disulfide reductase but also by regulating S-nitrosylation. Interestingly, different regulatory functions for the eight Cys residues have been introduced. Mutation of $\mathrm{C} 113$ inhibited $\mathrm{NF} \kappa \mathrm{B}$ signaling, whereas mutating the other Cys residues individually and especially simultaneously enhanced $\mathrm{NF} \kappa \mathrm{B}$ activity. Note that these seven Cys residues are all located in the TIR domain [93]. Different kinases, including the MAP kinases, are responsible for signal transduction and have been described to be susceptible to redox regulation. Trx1 and also Grx1 regulate ASK1 and downstream kinases such as ERK, JNK, and p38. The reduced oxidoreductases bind to ASK1 and thereby inhibit the enzymatic activity of the kinase. In case of Trxl, the protein interaction initiates ubiquitin-mediated degradation. Oxidation of the oxidoreductases induces the dissociation of the complex and restores kinase activity $[1,14,95,96]$. Interestingly, ASK1 is involved in TLR4 signaling and has however not been shown to be essential for other TLR pathways (Figure 3) [97, 98].

Following the cascade of cell signaling-transducing molecules, effector molecules are also posttranslationally modified, for example, the transcription factor $\mathrm{NF} \kappa \mathrm{B}$, which is highly regulated (for an overview see [36]). Comparable to other transcription factors such as AP1 and HIF1 $\alpha$, the DNA binding of $\mathrm{NF} \kappa \mathrm{B}$ is regulated by specific Cys residues that are susceptible to oxidation. The $\mathrm{NF} \kappa \mathrm{B}$ subunit p50 contains a cysteine residue in position 62 that promotes DNA binding in its reduced form. Alkylation, oxidation, or mutation to Ser or Ala of that particular cysteine inhibit DNA binding. It was shown that Cys62 can undergo Sglutathionylation and can also form a sulfenic acid [99]. Interestingly, various members of the Trx family have been shown to be involved in $\mathrm{NF} \kappa \mathrm{B}$ regulation. Even though it was shown that $\mathrm{NF} \kappa \mathrm{B}$ is a substrate for Trx1, Grxl, Grx2, and Nrx, the physiological impact during cellular signaling is poorly understood $[1,16,100,101]$. Overexpression of Grx3 in T-cells on the other hand inhibited $\mathrm{NF} \kappa \mathrm{B}-$ as well as AP1-induced gene expression [102]. Besides the DNA binding, the nuclear translocation is also redox-regulated. Reduced Trx1 inhibits the dissociation of the inhibitory $\mathrm{i} \kappa \mathrm{B} / \mathrm{NF} \kappa \mathrm{B}$ complex. Upon dissociation of the complex, $\mathrm{i} \kappa \mathrm{B}$ becomes phosphorylated and degraded by the proteasome. $\mathrm{NF} \kappa \mathrm{B}$ translocates into the nucleus (Figure 3). Apart from the regulation of transcription factors, gene expression can also be redox-regulated by, for example, the nuclear histone deacetylase and thus by chromatin remodelling [103]. 


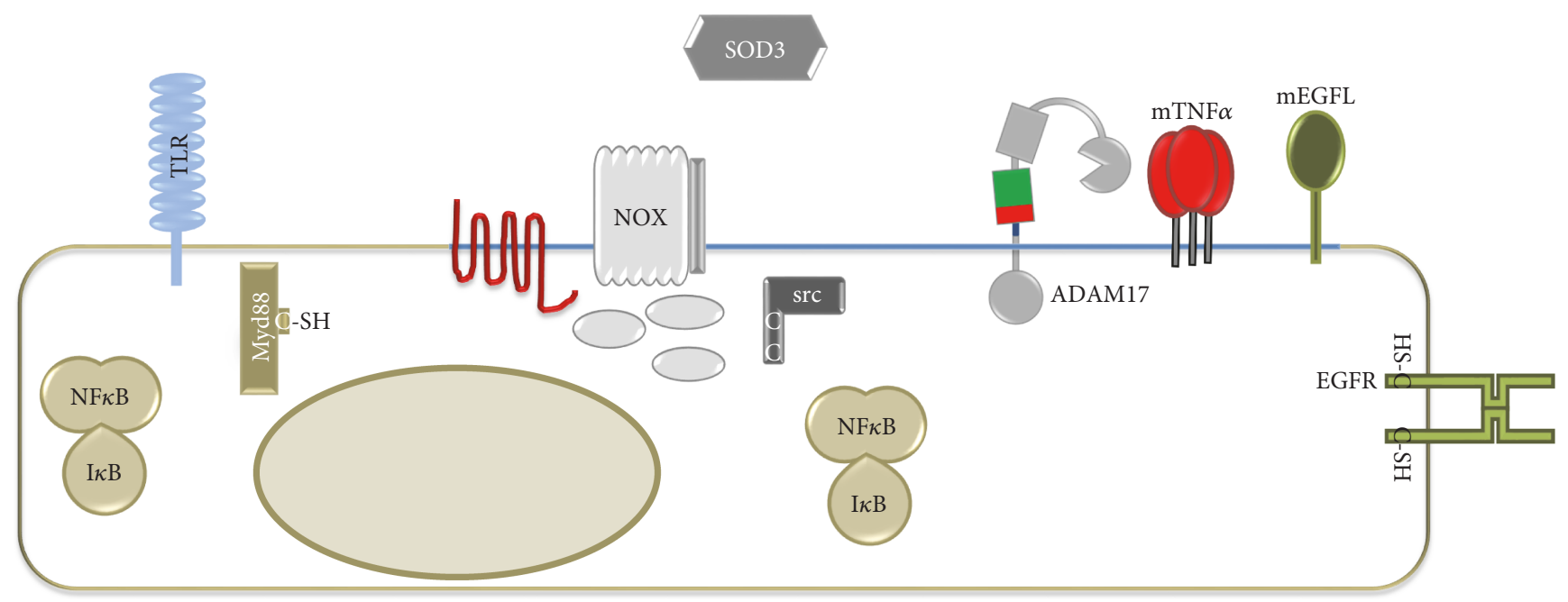

(a)

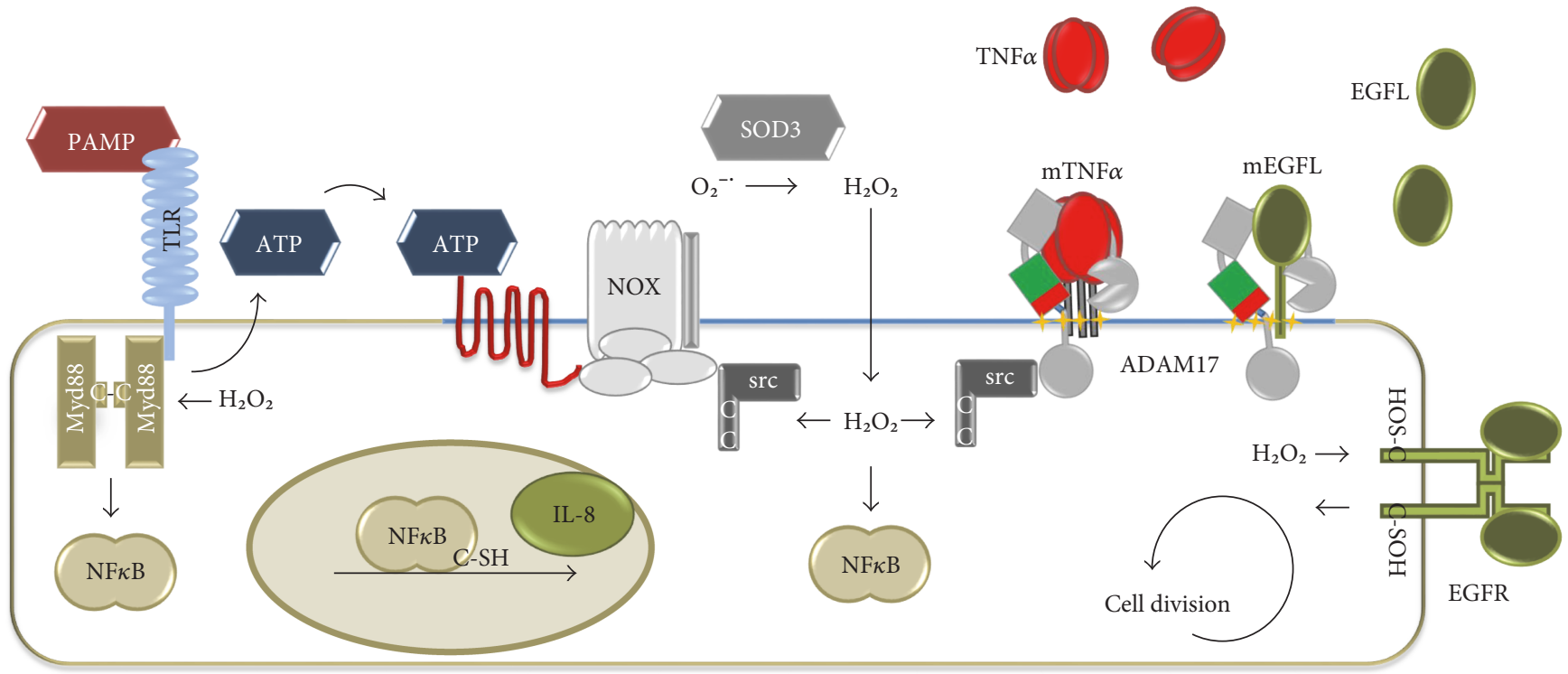

(b)

Figure 4: Pathogen detection and ROS-dependent defence and regeneration mechanisms. Epithelial cells are constantly exposed to pathogens. The redox state, the localisation, and the activity of different molecules and proteins are altered in the absence (a) or in the presence (b) of pathogens. Activation of TLRs by PAMPs and Myd88 recruitment induce secretion of ATP, which functions as danger signal and activates NOX. TLR and NOX activation both result in NF $\kappa$ B activation, via Myd88 or src, respectively. NF $\kappa$ B translocates to the nucleus and induces the expression of, for example, chemokines such as IL-8, promoting leukocyte recruitment. Myd88 dimerizes upon $\mathrm{H}_{2} \mathrm{O}_{2}$ exposure forming disulfide bridges. Src oxidation stabilizes the active conformation of the protease and the oxidation of cysteine residues near the ATP-binding site of the EGFR enhances its activity. Extracellular ATP leads to the activation of the shedding activity of ADAM17. ADAM17 releases soluble TNF $\alpha$ and ligands of the EGFR, such as TGF $\alpha$ and HB-EGF, from the cell surface, whereas TNF $\alpha$ promotes inflammation; signaling via the EGFR leads to regeneration due to induction of cell growth and division (mTNF $\alpha$ : membrane-bound TNF $\alpha$; mEGFRL: membrane-bound EGFR ligands).

\subsection{Redox Regulation of Inflammatory Mediators}

3.2.1. The NLRP3 Inflammasome Is Redox-Regulated. ROS were shown to control the NLRP3 inflammasome, a multiprotein complex that transfers the precursor of IL- $1 \beta$ in its mature and active form [26]. This process was shown to be regulated via Trx1. The cytosolic oxidoreductase binds thioredoxin-interacting protein (Txnip), a protein that was suggested to act as an endogenous inhibitor of Trx [104]. In this complex, Txnip is not able to interact with and activate
NLRP3. Upon oxidation of Trx1, the Trx1-Txnip complex dissociates and Txnip binds to NLRP3. Other mechanisms have been proposed in the regulation of the NLRP3 that is activated by various different stimuli, which are redoxindependent or might depend on the redox regulation by Trx1 and Txnip [44].

3.2.2. Ectodomain Shedding by ADAM17-A Regulatory Thiol Switch in ADAM17 in Inflammation and Tissue Regeneration. Phagocytes release various proinflammatory 


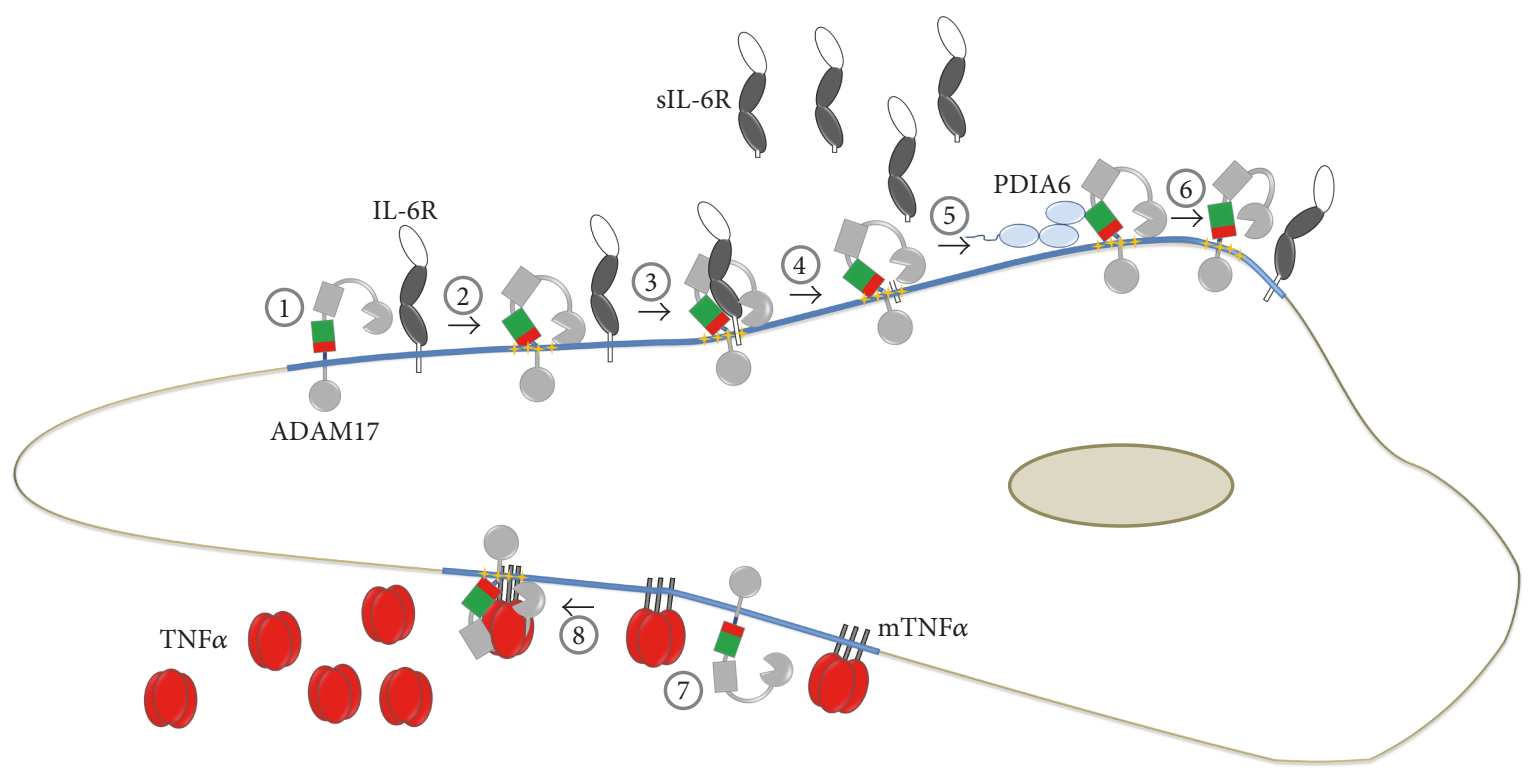

(a)
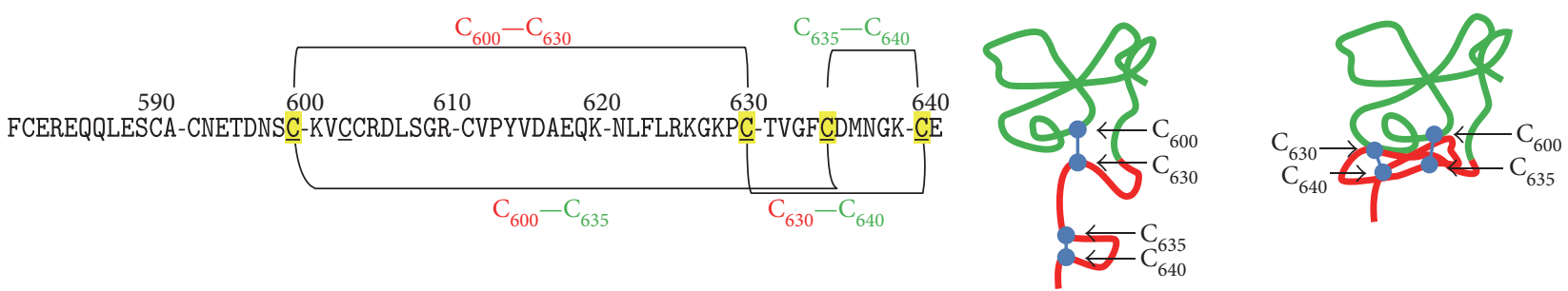

(b)

(c)

FIGURE 5: Thiol switch in ADAM17. (a) (1) ADAM17 is active within lipid rafts (blue line). (2) Different stimuli induce the exposure of phosphatidylserine (yellow stars), that interacts with the open and active conformation of the MPD. (3) This process allows ADAM17 to bind and (4) release substrates from the cell surface, for example, soluble interleukin 6 (sIL-6R). (5) Reduced extracellular protein disulfide isomerase PDIA6 catalyzes the disulfide isomerisation targeting the open MPD. (6) The resulting close and inactive structure of ADAM17 is not able to bind and process its substrates. (7) Membrane bound TNF $\alpha$ (mTNF $\alpha$ ) is another substrate of ADAM17, (8) which is released upon activation of ADAM17 and also promotes immune response and inflammation. (b) Primary structure of the MPD of human ADAM17, indicating the disulfide bridges involved in the thiol switch. The linear pattern $\left(\mathrm{C}_{600}-\mathrm{C}_{630}, \mathrm{C}_{635}-\mathrm{C}_{640}\right)$ constitutes the active, the overlaying pattern $\left(\mathrm{C}_{600}-\mathrm{C}_{635}, \mathrm{C}_{630}-\mathrm{C}_{640}\right)$, the inactive conformation. (c) Structural consequence of the thiol switch of ADAM17. The red-colored part is highly flexible in the open MPD and therefore not visible in the NMR data. The right structure represents the closed conformation of ADAM17 solved by NMR, in which the red part is packed tightly to the upper, green colored part of the MPD.

mediators to promote leukocyte recruitment and activation of the surrounding tissue. In this process, the IL-6R and the membrane-bound precursor of $\mathrm{TNF} \alpha$ are proteolytically cleaved by ADAM17; this shedding process leads to the generation of proinflammatory acting TNF $\alpha$ and sIL-6R (Figure 5). Shedding of IL-6R from apoptotic neutrophils generates an agonist of IL- 6 signaling, allowing the activation of cells, which do not express the membrane-bound IL-6R, but the ubiquitously expressed signaling subunits of the IL6 receptor complex gp130. This transsignaling mechanism promotes the attraction of monocytic cells and inflammation $[46,105,106]$. Moreover, ADAM17 cleaves members of the EGFR ligand family, which are essential for their function as growth factor and tissue regeneration [107-109]. Various ligands of the TLR and NOXs induce the activity of ADAM17 that is essential for immune response/inflammation and regeneration (Figure 4) $[47,83,110,111]$. In the healthy airway, TLR signaling can be upstream of exogenous ATP $[112,113]$. Duox1 is recruited to ATP-activated purinergic P2YR, followed by association with src, which becomes oxidized. Src in turn oxidizes and activates ADAM17, which amplifies EGFR activation and promotes immune defence and regeneration, involving an ERK1/2dependent production of the neutrophil attractant IL-8 (Figure 4) [114, 115]. Dysregulation of this pathway has been linked to inflammatory diseases, for example, cystic fibrosis and chronic inflammatory airway disease [116-120]. LPSinduced activation of ADAM17 in macrophages was shown to rely on the activity of PKC $\delta$ and p38. This activation is TLR4- and NOX2-dependent and targets the tyrosine kinase Mer, which inhibits inflammatory signaling during efferocytosis [121]. In primary monocytes, LPS-induced activation of ADAM17 is also mediated by ROS and p38 [122]. In hepatocytes, src activates NOX1, which in turn activates ADAM17 
that releases TGF $\alpha$ for the stimulation of the EGFR [123]. This process is caveolin-1-dependent. ADAM17, NOX1, and NOX2 are located and active within lipid rafts [75, 123-126]. The interaction of NOX1 and ADAM17 was shown by coimmunoprecipitation [127]. Interestingly, ADAM17 can also be activated by mitochondrial ROS in a src- and PKC-independent way via the activation of the P2Y receptor by ATP in fibroblast [128] and FAS-mediated apoptosis in neutrophils [129]. The activation of ADAM17 by members of the NOX family appears to be dependent on the activity of kinases such as src, PKC, p38, and/or ERK1/ 2. These kinases have been previously shown to be involved in the regulation of ADAM17, which is multilayered and only partially understood [130-133]. Interestingly, the extracellular part of ADAM17 is a target for regulatory events. In its mature form, the N-terminal catalytic domain is followed by a disintegrin domain, a membrane-proximal domain (MPD), and a conserved helical stalk region called conserved ADAM seventeen interaction sequence (CANDIS), a single transmembrane region and a cytoplasmic tail [134-137]. The MPD exists in two conformations that control the activity of the protease $[135,138]$. A linear order of two disulfide bridges $\left(\mathrm{C}_{600}-\mathrm{C}_{630}\right.$ and $\left.\mathrm{C}_{635}-\mathrm{C}_{640}\right)$ leads to an open, flexible structure, which is able to interact with the plasma membrane and substrates $[139,140]$. Reduced protein disulfide isomerase (PDI), a member of the Trx protein family, catalyzes the isomerisation to an overlaying pattern $\left(\mathrm{C}_{600}-\mathrm{C}_{635}\right.$ and $\left.\mathrm{C}_{630}-\mathrm{C}_{640}\right)$ causing a close, compact structure, which abrogates membrane binding and substrate recognition and thereby ADAM17 activity. In line, PDIA1 and PDIA6 were found to act as negative regulators [22, 135, 141] (Figure 5). The thiol switch as a general posttranslational mechanism to regulate the activity of members of the ADAM family appears to be unlikely since ADAM17 and its closest relative ADAM10 are atypical members of the protein family. The other members lack the redox-regulated MPD domain and contain a cysteine-rich and an EGF-like domain instead $[134,136]$. Therefore, no comparable posttranslational thiol switch can be expected and indeed so far no posttranslational regulation of these proteases via NOX, ROS in general or specific oxidoreductases has been described to our knowledge. It is however possible that the activity of ADAM10, which contains a MPD homolog to the one of ADAM17, is regulated via a comparable thiol switch. The isolated open form of the ADAM17-MPD can be expressed as a soluble protein and the closed from can be obtained by refolding or by enzymatic catalysis by PDIs, converting the open form to the close form. So far, no open ADAM10-MPD was obtained by expression in E. coli (unpublished observations), indicating that no open form exists and/or that the interaction with the N-terminal located disintegrin domain might be tighter and more important for the stabilization than in ADAM17. This might point against a regulatory thiol switch of ADAM10 and fit to the observation that the activity of ADAM17 is more strongly regulated than the activity of ADAM10, which can be constitutively active. However, a thiol switch in ADAM10 cannot be excluded since reports indicate that the shedding activity of ADAM10 can indeed be stimulated by ROS $[142,143]$. PDIs attack the CKVC motive in the MPD of ADAM17, which is evolutionarily conserved in vertebrates, but not present in animals such as pike, hamadryad, or drosophila. ADAM10 on the other hand contains the CHVC motif that is also conserved in evolutionary higher animals. This indicates that during evolution with increased complexity and potential higher risks of uncontrolled substrate release, a regulatory mechanism of the protease became essential. Note that the posttranslational regulation of proteins by a thiol switch in their ectodomains is not unique for metalloproteases. For example, CD30 contains no CKVC or CHVC motive and is targeted by Trx1 which results in an altered ligand binding [144], whereas ADAM17 becomes inactivated by the thiol switch, and $\beta 1$ and $\beta 3$ integrins become activated [145]. Intriguingly, this can be catalyzed by identical PDIs, such as PDIA1 and PDIA6. Since $\beta 1$ and $\beta 3$ integrins contain numerous CXXC motives, but not a CKVC motive, PDIs may recognize different CXXC motives.

\subsubsection{The Immunomodulatory Functions of HMGB1 Are} Regulated via Three Cys Residues. HMGB1 comprises the HMG A box essential for DNA binding, the HMG B box essential for DNA binding and proinflammatory functions (i.e., amino acids 89 to 108), and an acidic C-terminus [146]. HMGB1 conducts various functions depending on its localization. Nuclear HMGB1 is, for instance, involved in DNA organization and gene transcription; cytosolic HMGB1 regulates the inflammasome, pyroptosis, and the autophagy/ apoptosis balance; and extracellular HMGB1 has been described as one of the first DAMPs with proinflammatory activities in distinct cell culture and animal models, as well as in patients suffering from sterile or infectious inflammation (reviewed in [147]). LPS-stimulated monocytes secrete HMGB1 nonclassically via exocytosis of secretory lysosomes induced by lysophosphatidylcholine that is produced comparably late during inflammation [148]. Interestingly, oleanolic acid is a natural inhibitor of HMGB1 release by LPSstimulated RAW264.7 macrophages. Even though the exact mechanism is not fully understood, it involves the activation of Nrf2 that binds to the ARE of heme-oxygenase-1 [149]. HMGB1 is also released during necrosis or cell damage, however, not during apoptosis [150]. HMGB1 leakage has also been associated with high levels of superoxide and peroxynitrite [151]. HMGB1 has three Cys residues in the positions 23,45 , and 106 . We have recently shown that TNF $\alpha$-induced HMGB1 secretion from HEK293 cells does not depend on the redox state of the protein [51]. Note that the translocation from the nucleus to the cytosol depends on posttranslational modifications such as acetylation and potentially also thiol oxidation [152, 153]. Especially, the substrate interaction and the distinct functions of HMGB1 are redox-regulated. An intramolecular disulfide between Cys23 and Cys45, as well as the reduced Cys106, located in the HMG B box, is essential for TLR4/MD2 binding, macrophage activation, and cytokine release. Fully oxidized, that is, three sulfonates and fully reduced HMGB1 do not affect TLR4 signaling $[154,155]$. However, the latter shows chemotactic activity by interacting with the chemokine CXCL12 that binds to the chemokine receptor CXCR4. Interestingly, a redox- 
inactive mutant, containing three Ser residues instead of Cys residues, is even more active in terms of leukocyte recruitment than the fully reduced protein [151, 156, 157]. Even though the redox state of the protein has been linked to particular substrates and functions in different compartments, the regulation of the thiol switches of HMGB1 has not been fully understood. It is however clear that these switches constitute physiological mechanisms to regulate and modulate the inflammatory activities of the protein. Interestingly, HMGB1 was shown to interact with the oxidoreductase glutaredoxin [153] and also Trx1 was shown to be able to reduce the intramolecular disulfide $[153,158]$.

3.2.4. Extracellular Redoxins Act as Immune Mediators. Distinct members of the Trx family of proteins have been described to be secreted in various cell and animal models, as well as in patients suffering, for example, from inflammatory diseases (reviewed in [1]). Trx1 was originally known as T-cell leukemia-derived factor that was shown to induce the IL2 receptor [159] and the expression of various cytokines [160]. In addition, the truncated Trx80, formerly characterized as eosinophil cytotoxicity-enhancing factor, has been shown to be secreted functioning as cytoand chemokine [161]. Apart from its cytokine and chemoattractant functions, there are also controversial findings that imply an anti-inflammatory role. One potential mechanism could involve the regulation of the proinflammatory macrophage migration inhibitor factor (MIF). Interestingly, MIF also belongs to the Trx family of proteins and is involved in the innate immune response [162]. Prx2 is a highly expressed intracellular peroxidase that is released from myeloid cells in response to inflammatory stimuli. Once released from cells, Prx2 has proinflammatory activity, essentially behaving as a DAMP [52]. Intriguingly, the release of Prx2 from cells under inflammatory conditions is mediated by two types of thiol modifications involving all three cysteine residues. Prx 2 is released from LPS-stimulated mouse macrophages in a glutathionylated form [52]. A second thiol redox change involves oxidation of two cysteine residues forming a disulfide bond, which induces protein dimerization and results in its release from the cell via exosomes [51]. Mutation of either one of the Cys residues involved in the disulfide bridge prevents secretion of the enzyme. Recombinant Prx2 is able to stimulate the release of TNF $\alpha$ from both mouse macrophages and primary human monocytes [51, 52]. Prx1 is also released from mouse macrophages in response to LPS. It was detected in the secretome of LPS-stimulated cells in a glutathionylated form and also exhibits the reliance on Cys oxidation for the release from cells. Thus, it appears that redox modulation regulates the release of these enzymes from cells contributing to the local inflammatory response. In addition, redox changes provide a novel mechanism by which proteins are processed for export from cells during inflammation, at least for Prx1 and 2. As such, there is the potential for the development of novel therapeutic strategies for modulating the redox environment in order to dampen the inflammatory response. Note that also Trx1 was detected in the proteomic analysis.

\section{Clinical Significance}

Biomarkers for inflammatory disorders include oxidative modifications of DNA, proteins, and lipids and have been reviewed in [25]. Even though the redox state of particular proteins is not easily accessible in patient material due to a general lack of specific tools, the expression, localization, and activity of redox enzymes, for example, Trx family proteins have been studied in various diseases (Table 2) [1]. Moreover, different redox enzymes have been identified as potential targets for therapy in a number of diseases, including inflammatory disorders. The neutrophil-derived myeloperoxidase is known as one of the most potent oxidantproducing proteins. Increased MPO activity and excessive production of hypochlorous acid contribute to chronic inflammation and organ damage in many tissues [163, 164]. Elevated expression was described in cardiovascular disease $[165,166]$, presumably due to its oxidation of lowand high-density lipoprotein [167], as well as rheumatoid arthritis [168]. MPO also seems to be a risk factor in heart failure and acute coronary syndrome [169]. In tracheal aspirates, elevated levels of chlorinated proteins, trace markers of MPO activity, are believed to contribute to chronic lung infection in infants [170]. Accordingly, many studies have been conducted in search of nontoxic, reversible MPO inhibitors preferably binding the native protein [171-173]. Interestingly, neutrophil extracellular traps are decorated with active MPO [174] and are associated with chronic inflammation in many diseases too [175]. Neuron-derived MPO seems to contribute to Alzheimer's disease, a neurodegenerative disorder that has also been linked to neuroinflammation [176]. It is worth mentioning that elevated MPO activity is associated with an overall better outcome in specific cancer chemotherapy [177]. However, MPO is tightly linked to many clinical observations but redox signaling pathways beyond localized $\mathrm{HOCl}-$ mediated oxidation remain to be studied in most pathologies.

The heme protein lactoperoxidase is found in secretion liquids such as tears, milk, and saliva [178]. Saliva in particular has been thoroughly investigated in different oral diseases. The effect of orally administered LPO was weak on periodontitis and bacteriological profile [179]. However, LPO activity itself seems to be increased in periodontitis [180] although thiocyanate is not increased in this disease [181]. There is no association between recurrent aphthous stomatitis and salivary thiocyanate levels [182] but patients with aphtous ulcers have significantly lower oral LPO levels [183]. Xylitol increases oral LPO activity but not thiocyanate levels, and this may account for the cariostatic effect of xylitol. Also, compounds with a 3,4-dihydroxyphenyl structure significantly enhance LPO activity [184] but the clinical implication of this finding remains to be elucidated. Frequent tobacco consumption puts people at risk for oral cancer [185]. Saliva levels of thiocyanate are strongly increased in smokers [186] whereas LPO activity is blocked by tobacco smoke [187]. Whether LPO is crucial in oral carcinogenesis currently remains unknown.

The seven NOX members generate superoxide and secondarily $\mathrm{H}_{2} \mathrm{O}_{2}$. In chronic granulomatous disease, that is, a 
TABle 2: Clinical implications of redox enzymes.

\begin{tabular}{|c|c|c|c|c|}
\hline Protein & Reactive species & Pathology & Levels/role & Reference \\
\hline \multirow[t]{6}{*}{ Myeloperoxidase } & $\begin{array}{c}\text { Production of } \\
\text { hypochlorous and } \\
\text { hypobromous acid }\end{array}$ & $\begin{array}{l}\text { Alzheimer's disease, } \\
\text { Parkinson's disease }\end{array}$ & Beneficial & {$[172,258]$} \\
\hline & & Arteriosclerotic plaques & Increased & [259] \\
\hline & & $\begin{array}{c}\text { Breast cancer and } \\
\text { chemotherapy }\end{array}$ & Activity increased/beneficial & {$[177]$} \\
\hline & & Cardiovascular disease & Increased (plasma) & {$[165]$} \\
\hline & & $\begin{array}{l}\text { Chronic lung infection } \\
\text { in preterm infants }\end{array}$ & Increased (tracheal aspirates) & {$[170]$} \\
\hline & & Rheumatoid arthritis & Increased (plasma, synovial fluid) & {$[168]$} \\
\hline \multirow[t]{4}{*}{ Lactoperoxidase } & $\begin{array}{c}\text { Production of } \\
\text { hypothiocyanate }\end{array}$ & Chronic peridontitis & $\begin{array}{l}\text { Oral LPO administration had } \\
\text { no effect on disease }\end{array}$ & [179] \\
\hline & & $\begin{array}{l}\text { Peridontitis in diabetes } \\
\text { mellitus type I }\end{array}$ & Activity increased (saliva) & {$[180]$} \\
\hline & & Recurrent aphtous stomatitis & Decreased (saliva) & {$[183]$} \\
\hline & & Smoking & Activity decreased (saliva) & {$[187]$} \\
\hline \multirow[t]{6}{*}{ NADPH oxidase } & $\begin{array}{l}\text { Production of superoxide } \\
\text { and secondary hydrogen } \\
\text { peroxide }\end{array}$ & Acute myocardial infarct & $\begin{array}{l}\text { Increased (heart tissue), activity } \\
\text { increased (heart tissue), increased } \\
\text { (saphenous vein) }\end{array}$ & {$[192-194]$} \\
\hline & & Cardiovascular disease & Increased (serum)/detrimental & {$[202]$} \\
\hline & & $\begin{array}{c}\text { Chronic granulomatous } \\
\text { disease }\end{array}$ & $\begin{array}{l}\text { Activity decreased (peripheral } \\
\text { blood neutrophils)/detrimental }\end{array}$ & [189] \\
\hline & & Diabetes nephropathy & Increased/phase II trial completed & [199] \\
\hline & & Melanoma & $\begin{array}{l}\text { Similar (melanoma tissue)/no } \\
\text { correlation with invasiveness }\end{array}$ & {$[201]$} \\
\hline & & Retinopathy & Increased/detrimental & {$[260]$} \\
\hline \multirow[t]{8}{*}{$\begin{array}{l}\text { Nitric oxide } \\
\text { synthase }\end{array}$} & Production of nitric oxide & Asthma & $\begin{array}{l}\text { Inhibition detrimental/inhibition } \\
\text { beneficial/inhibition had no effect }\end{array}$ & {$[224-226]$} \\
\hline & & Breast cancer & Increased/none & {$[234]$} \\
\hline & & Head and neck cancer & $\begin{array}{c}\text { Increased/detrimental } \\
\text { (in respective cancer tissue) }\end{array}$ & [235] \\
\hline & & $\begin{array}{l}\text { Heart disease and rejected } \\
\text { transplants }\end{array}$ & Increased (heart tissue) & {$[228-232]$} \\
\hline & & Melanoma & Increased/detrimental & {$[233]$} \\
\hline & & Migraine & $\begin{array}{l}\text { Inhibition beneficial/inhibition } \\
\text { had no effect }\end{array}$ & {$[220-222]$} \\
\hline & & Rheumatoid arthritis & Increased/inhibition beneficial & {$[227]$} \\
\hline & & Sepsis & $\begin{array}{l}\text { Inhibition detrimental/beneficial/no } \\
\text { effect (serum) }\end{array}$ & [213-217] \\
\hline \multirow[t]{7}{*}{ Peroxiredoxins } & $\begin{array}{l}\text { Decomposition of } \mathrm{H}_{2} \mathrm{O}_{2} \\
\text { redox signaling }\end{array}$ & Alzheimer's disease & $\begin{array}{l}\text { Prx1/Prx2 increased (brain tissue), } \\
\text { Prx2 activity decreased (blood), } \\
\text { Prx3 decreased (brain tissue) }\end{array}$ & {$[241-243,248]$} \\
\hline & & Cataracts & Prx6 decreased (eye tissue) & {$[250]$} \\
\hline & & Diabetes mellitus type II & Prx4 increased (serum) & {$[252]$} \\
\hline & & Diabetic retinopathy & Prx1 increased (vitreous biopsy) & {$[251]$} \\
\hline & & Glaucoma & Prx6 increased (eye tissue) & [249] \\
\hline & & Lung cancer & $\begin{array}{c}\text { Prx1 increased, Prx3 increased } \\
\text { (cancer tissue) }\end{array}$ & {$[254,255]$} \\
\hline & & Parkinson's disease & Prx2 increased & {$[244]$} \\
\hline
\end{tabular}


group of hereditary defects that result in an increased susceptibility to various bacterial and fungal infections, a functional NOX attenuation leads to life-threatening infections [188]. Hereby, the degree of attenuation governs patient prognosis [189]. Genetic defects in components of NOX2 have been linked to chronic granulomatous disease [69, 84, 190]. NOX proteins have been associated with cardiovascular risk factors contributing to atherosclerosis, vascular dysfunction, hypertension, vascular hypertrophy, and thrombosis [191]. An upregulation of NOX2 was detected upon myocardial infarct in cardiomyocytes [192] and in failing, however not in nonfailing hearts [193] as well as in saphenous veins of patients with heart failure [194]. NOX2-enriched veins may contribute to endothelial dysfunction [195]. Accordingly, targeting NAPDH oxidases in cardiovascular disease was suggested to be of clinical benefit [196]. NOX can be activated in the blood vessel walls via angiotensin II [197] causing cardiovascular disease [198]. NOX is also a target in diabetic nephropathy [199], and an orally administrable inhibitor (GKT137831) has completed phase 2 trial (NCT02010242) but results have not yet been published. NOX1 inhibition is also a therapeutic strategy against hypertension [200] that is tested in clinical trials for cardiovascular conditions [201]. Particularly, the NOX inhibitor Dextromethorphan reduced hypertension in a multicenter trial [202]. In malignancies, NOX4 is elevated in brain, colorectal, gastric, lung, and pancreatic cancer [203]. Accordingly, NOX enzymes also constitute promising targets in cancer therapy [204]. Gentian violet, a NOX1 inhibitor, showed promising effects in the palliation of a melanoma patient [205]. Yet, NOX1 does not correlate with melanoma invasiveness [201]. This substance was also successfully used to treat the inflammatory skin condition erythema multiforme [206].

The importance of NO'in human health was first suggested in human ileostomy effluents showing elevated nitrite concentrations [207]. Its role in acute and chronic inflammation [208] has been investigated ever since [209]. Elevated levels of NO contribute to pathologies linked to inflammation, for example, asthma, arthritis, multiple sclerosis, transplant rejection, stroke, and neurodegenerative diseases [30, 210]. Glucocorticoids inhibit NOS [211] and thereby production of $\mathrm{NO}^{\bullet}$ that has been implicated in sepsis [212]. However, clinical trials on NOS inhibition gave inconclusive results demonstrating either a negative [213], a positive [214], or no effect [215] on survival of septic patients. Short-term improvement was shown following methylene blue administration [216] whereas LNNA was ineffective [217]. NOS inhibition with L-arginine analogues such as ${ }_{\mathrm{L}}$ NMMA gave a more confident response with regard to cardiovascular parameters in septic patients [218]. However, the mortality rate in a phase III trial was elevated [219]. Nonetheless, this substance was shown to be effective in treating migraine attacks in a placebo-controlled clinical study [220]. Clinical trials using the NOS inhibitor GW274150 did not confirm these results, neither as early intervention [221] nor in a prophylactic therapy [222]. NOS genotype (high numbers of trinucleotides) and exhaled $\mathrm{NO}^{\bullet}$ are associated with asthma [223]. The NOS inhibitor L-NIL-TA strongly reduced the amount of exhaled $\mathrm{NO}^{\bullet}$ in asthmatic patients without measurable vascular side effects [224]. This finding was confirmed in another clinical trial using GW274150 with no significant improvement of the asthmatic symptoms [225]. Administration of ${ }_{\mathrm{L}}$ NMMA amplified bradykinin-induced asthma in volunteers [226]. GW274150 also reduced synovial joint thickness and vascularity in patients with rheumatoid arthritis [227]. In general, NOS is linked to heart disease [228]. NOS is elevated in heart tissue of patients experiencing hibernating myocardium [229], in transplanted coronary arteries [230], in rejected transplants [231], and in tissue from human heart failure [232]. NOS expression also promotes melanoma cell proliferation and is associated with poor patient survival [233]. In breast cancer [234] but not head and neck cancer [235], NOS expression corresponds to stage and invasiveness.

Oxidants have long been suggested to play a role in the central nervous system [236]. Inflammation is a key event in the onset and stage of brain disease, such as multiple sclerosis [237]. Prx1 is expressed in glial cells, whereas Prx2 expression was predominantly found in neurons [238-240]. The expression levels of both Prx1 and Prx 2 are elevated in patients suffering from Alzheimer's disease [241, 242]; moreover, Prx2 and Prx6 are more oxidized in the brain [243]. Additionally, Prx2 peroxidase activity was found to be inhibited by S-nitrosylation [244] and phosphorylation [245] in Alzheimer's disease. Prx2 expression is also increased in Parkinson's disease [246, 247], whereas the Prx3 expression is decreased in the latter [248]. Prx expression is also regulated in ocular pathologies. Alongside with inflammation, Prx6 is increased in the trabecular meshwork in glaucoma patients [249] and correlates negatively with severity of cataracts [250]. Diabetic retinopathy is associated with elevated levels of Prx1 [251], with the diabetic risk being associated with increased serum concentrations of Prx4 [252]. Peroxiredoxins are regulated in cancer, a condition that heavily modulates the inflammatory environment to enhance growth [253]. Tissue and serum of lung cancer patients showed elevated levels of Prx1 and Prx3, respectively [254, 255]. Autoantibodies against Prx6 have also been shown to be of prognostic value in esophageal cancer [256]. So far, no therapeutic strategies to target Prxs were conducted.

\section{Future Perspective}

It is of great interest to understand the mechanisms of cellular signaling and how they are regulated under physiological, but generally also under pathological conditions. Even though it has been established that redox regulation and oxidative Cys modifications are essential for signal transduction and cellular processes, the identification and characterization of specific thiol switches and their enzymatic regulation constitute a big challenge in the field. Particularly, the field lacks time- and spatial-resolved in vivo techniques for the analysis of (i) the levels and distribution of different ROS and RNS, (ii) the particular redox state of proteins, and (iii) the impact of redox signaling on complex signaling circuits and networks. The innate and the adaptive immune responses are tightly controlled and depend on the enzymatic production of superoxide, hydrogen peroxide, hydrogen sulfide, and 
nitric oxide. However, not many redox-regulated protein substrates are known. Future research will identify these substrates and particular thiol switches, including intracellular, as well as membrane and extracellular proteins and the underlying regulatory mechanisms. Intriguingly, the extracellular space contains redox-active enzymes and molecules such as glutathione. It is tempting to speculate that the inflammatory response does not only constitute intracellular redox-signaling cascades but also depends on extracellular signal transduction within the microenvironment of distinct cell types.

\section{Abbreviations}

$\begin{array}{ll}\text { ADAM17: } & \text { A disintegrin and metalloproteinase } 17 \\ \text { DAMP: } & \text { Damage-associated molecular pattern } \\ \text { DUOX: } & \text { Dual oxidase } \\ \text { EGF: } & \text { Epidermal growth factor } \\ \text { FAD: } & \text { Flavin-adenine dinucleotide } \\ \text { Gpx: } & \text { Glutathione peroxidase } \\ \text { Grx: } & \text { Glutaredoxin } \\ \text { HMGB1: } & \text { High-mobility group protein } 1 \\ \text { IL: } & \text { Interleukin } \\ \text { IRAK: } & \text { Interleukin-1 receptor-associated kinase } \\ \text { LPO: } & \text { Lactoperoxidase } \\ \text { LPS: } & \text { Lipopolysaccharide } \\ \text { MAPK: } & \text { Mitogen-activated protein kinase } \\ \text { MIF: } & \text { Macrophage migration inhibitor factor } \\ \text { MPD: } & \text { Membrane-proximal domain } \\ \text { MPO: } & \text { Neutrophil-derived myeloperoxidase } \\ \text { Myd88: } & \text { Myeloid differentiation primary response } 88 \\ \text { NLR: } & \text { NOD-like receptors } \\ \text { NOS: } & \text { Nitric oxide synthase } \\ \text { NOX: } & \text { NADPH oxidase } \\ \text { Nrx: } & \text { Nucleoredoxin } \\ \text { PAMP: } & \text { Pathogen-associated molecular pattern } \\ \text { Prx: } & \text { Peroxiredoxin } \\ \text { SOD: } & \text { Superoxide dismutase } \\ \text { TIR: } & \text { Toll/IL-1 receptor } \\ \text { TNF: } & \text { Tumor necrosis factor } \\ \text { TLR: } & \text { Toll-like receptor } \\ \text { Trx: } & \text { Thioredoxin } \\ \text { Txnip: } & \text { Thioredoxin-interacting protein } \\ \text { ROS: } & \text { Reactive oxygen species } \\ \text { RNS: } & \text { Reactive nitrogen species. } \\ & \end{array}$

\section{Conflicts of Interest}

The authors declare that there is no conflict of interests regarding the publication of this paper.

\section{Acknowledgments}

Inken Lorenzen and Eva-Maria Hanschmann gratefully acknowledge the financial support by the priority program (SPP) 1710, founded by the German Research Foundation (DFG) to investigate thiol switches in cellular physiology. Lisa Mullen gratefully acknowledges financial support from the Brighton and Sussex Medical School, the University of
Sussex Research Development Fund and the University of Brighton. Sander Bekeschus was supported by the German Federal Ministry of Education and Research (BMBF; grant no. 03Z22DN11).

\section{References}

[1] E.-M. Hanschmann, J. R. Godoy, C. Berndt, C. Hudemann, and C. H. Lillig, "Thioredoxins, glutaredoxins, and peroxiredoxins-molecular mechanisms and health significance: from cofactors to antioxidants to redox signaling," Antioxidants \& Redox Signaling, vol. 19, no. 13, pp. 1539-1605, 2013.

[2] L. I. Leichert and T. P. Dick, "Incidence and physiological relevance of protein thiol switches," Biological Chemistry, vol. 396, no. 5, pp. 389-399, 2015.

[3] L.-O. Klotz, P. Schroeder, and H. Sies, "Peroxynitrite signaling: receptor tyrosine kinases and activation of stressresponsive pathways," Free Radical Biology \& Medicine, vol. 33, no. 6, pp. 737-743, 2002.

[4] P. Calcerrada, G. Peluffo, and R. Radi, "Nitric oxide-derived oxidants with a focus on peroxynitrite: molecular targets, cellular responses and therapeutic implications," Current Pharmaceutical Design, vol. 17, no. 35, pp. 3905-3932, 2011.

[5] C. Berndt, C. H. Lillig, and L. Flohé, "Redox regulation by glutathione needs enzymes," Frontiers in Pharmacology, vol. 5, p. 168, 2014.

[6] D. P. Jones, "Redefining oxidative stress," Antioxidants \& Redox Signaling, vol. 8, no. 9-10, pp. 1865-1879, 2006.

[7] C. C. Winterbourn and D. Metodiewa, "Reactivity of biologically important thiol compounds with superoxide and hydrogen peroxide," Free Radical Biology and Medicine, vol. 27, no. 3-4, pp. 322-328, 1999.

[8] M. Deponte and C. H. Lillig, "Enzymatic control of cysteinyl thiol switches in proteins," Biological Chemistry, vol. 396, no. 5, pp. 401-413, 2015.

[9] L. E. S. Netto and F. Antunes, “The roles of peroxiredoxin and thioredoxin in hydrogen peroxide sensing and in signal transduction," Molecules and Cells, vol. 39, no. 1, pp. 65-71, 2016.

[10] T. C. Laurent, E. C. Moore, and P. Reichard, "Enzymatic synthesis of deoxyribonucleotides. IV. Isolation and characterization of thioredoxin, the hydrogen donor from Escherichia coli b," The Journal of Biological Chemistry, vol. 239, pp. 3436-3444, 1964.

[11] A. Holmgren, "Glutathione-dependent synthesis of deoxyribonucleotides. Characterization of the enzymatic mechanism of Escherichia coli glutaredoxin," The Journal of Biological Chemistry, vol. 254, no. 9, pp. 3672-3678, 1979.

[12] L. Bräutigam, L. D. Jensen, G. Poschmann et al., "Glutaredoxin regulates vascular development by reversible glutathionylation of sirtuin 1," Proceedings of the National Academy of Sciences of the United States of America, vol. 110, no. 50, pp. 20057-20062, 2013.

[13] D. A. Mitchell and M. A. Marletta, "Thioredoxin catalyzes the S-nitrosation of the caspase-3 active site cysteine," Nature Chemical Biology, vol. 1, no. 3, pp. 154-158, 2005.

[14] M. Saitoh, H. Nishitoh, M. Fujii et al., "Mammalian thioredoxin is a direct inhibitor of apoptosis signal-regulating kinase (ASK) 1," The EMBO Journal, vol. 17, no. 9, pp. 2596-2606, 1998.

[15] Y. Mikami, N. Shibuya, Y. Kimura, N. Nagahara, Y. Ogasawara, and H. Kimura, "Thioredoxin and dihydrolipoic acid 
are required for 3-mercaptopyruvate sulfurtransferase to produce hydrogen sulfide," The Biochemical Journal, vol. 439, no. 3, pp. 479-485, 2011.

[16] J. R. Matthews, N. Wakasugi, J. L. Virelizier, J. Yodoi, and R. T. Hay, "Thioredoxin regulates the DNA binding activity of NF- $\kappa \mathrm{B}$ by reduction of a disulphide bond involving cysteine 62," Nucleic Acids Research, vol. 20, no. 15, pp. 38213830, 1992.

[17] M. C. Sobotta, W. Liou, S. Stöcker et al., "Peroxiredoxin-2 and STAT3 form a redox relay for $\mathrm{H} 2 \mathrm{O} 2$ signaling," Nature Chemical Biology, vol. 11, no. 1, pp. 64-70, 2015.

[18] Y. Funato, T. Michiue, M. Asashima, and H. Miki, "The thioredoxin-related redox-regulating protein nucleoredoxin inhibits Wnt-beta-catenin signalling through dishevelled," Nature Cell Biology, vol. 8, no. 5, pp. 501-508, 2006.

[19] L. Bräutigam, L. D. Schütte, J. R. Godoy et al., "Vertebratespecific glutaredoxin is essential for brain development," Proceedings of the National Academy of Sciences of the United States of America, vol. 108, no. 51, pp. 20532-20537, 2011.

[20] M. Gellert, S. Venz, J. Mitlöhner, C. Cott, E.-M. Hanschmann, and C. H. Lillig, "Identification of a dithiol-disulfide switch in collapsin response mediator protein 2 (CRMP2) that is toggled in a model of neuronal differentiation," The Journal of Biological Chemistry, vol. 288, no. 49, pp. 3511735125, 2013.

[21] T. Hayashi, Y. Funato, T. Terabayashi et al., "Nucleoredoxin negatively regulates Toll-like receptor 4 signaling via recruitment of flightless-I to myeloid differentiation primary response gene (88)," The Journal of Biological Chemistry, vol. 285, no. 24, pp. 18586-18593, 2010.

[22] S. H. Willems, C. J. Tape, P. L. Stanley et al., "Thiol isomerases negatively regulate the cellular shedding activity of ADAM17," The Biochemical Journal, vol. 428, no. 3, pp. 439-450, 2010.

[23] C. H. Lillig and C. Berndt, "Glutaredoxins in thiol/disulfide exchange," Antioxidants \& Redox Signaling, vol. 18, no. 13, pp. 1654-1665, 2013.

[24] C. Berndt, J.-D. Schwenn, and C. H. Lillig, "The specificity of thioredoxins and glutaredoxins is determined by electrostatic and geometric complementarity," Chemical Science, vol. 6, no. 12, pp. 7049-7058, 2015.

[25] Y. Lei, K. Wang, L. Deng, Y. Chen, E. C. Nice, and C. Huang, "Redox regulation of inflammation: old elements, a new story," Medicinal Research Reviews, vol. 35, no. 2, pp. 306340, 2015.

[26] J. M. Abais, M. Xia, Y. Zhang, K. M. Boini, and P.-L. Li, "Redox regulation of NLRP3 inflammasomes: ROS as trigger or effector?," Antioxidants \& Redox Signaling, vol. 22, no. 13, pp. 1111-1129, 2015.

[27] C. K. Sen and S. Roy, "Redox signals in wound healing," Biochimica et Biophysica Acta (BBA) - General Subjects, vol. 1780, no. 11, pp. 1348-1361, 2008.

[28] O. Kabil, N. Motl, and R. Banerjee, "H2S and its role in redox signaling," Biochimica et Biophysica Acta (BBA) - Proteins and Proteomics, vol. 1844, no. 8, pp. 1355-1366, 2014.

[29] M. Bhatia, "H2S and inflammation: an overview," Handbook of Experimental Pharmacology, vol. 230, pp. 165-180, 2015.

[30] H. Kleinert, A. Pautz, K. Linker, and P. M. Schwarz, "Regulation of the expression of inducible nitric oxide synthase," European Journal of Pharmacology, vol. 500, no. 1-3, pp. 255-266, 2004.
[31] A. Pautz, J. Art, S. Hahn, S. Nowag, C. Voss, and H. Kleinert, "Regulation of the expression of inducible nitric oxide synthase," Nitric Oxide: Biology and Chemistry, vol. 23, no. 2, pp. 75-93, 2010.

[32] D. A. Wink, H. B. Hines, R. Y. Cheng et al., "Nitric oxide and redox mechanisms in the immune response," Journal of Leukocyte Biology, vol. 89, no. 6, pp. 873-891, 2011.

[33] B. Brüne, N. Dehne, N. Grossmann et al., "Redox control of inflammation in macrophages," Antioxidants \& Redox Signaling, vol. 19, no. 6, pp. 595-637, 2013.

[34] Z. Prokopowicz, J. Marcinkiewicz, D. R. Katz, and B. M. Chain, "Neutrophil myeloperoxidase: soldier and statesman," Archivum Immunologiae et Therapiae Experimentalis (Warsz), vol. 60, no. 1, pp. 43-54, 2012.

[35] P. Nagy, S. S. Alguindigue, and M. T. Ashby, "Lactoperoxidase-catalyzed oxidation of thiocyanate by hydrogen peroxide: a reinvestigation of hypothiocyanite by nuclear magnetic resonance and optical spectroscopy," Biochemistry (Moscow), vol. 45, no. 41, pp. 12610-12616, 2006.

[36] M. V. Gattas, R. Forteza, M. A. Fragoso et al., "Oxidative epithelial host defense is regulated by infectious and inflammatory stimuli," Free Radical Biology \& Medicine, vol. 47, no. 10, pp. 1450-1458, 2009.

[37] M. Jaeger, M. H. T. Stappers, L. A. B. Joosten, I. C. Gyssens, and M. G. Netea, "Genetic variation in pattern recognition receptors: functional consequences and susceptibility to infectious disease," Future Microbiology, vol. 10, no. 6, pp. 989-1008, 2015.

[38] B. K. Davis, H. Wen, and J. P.-Y. Ting, "The inflammasome NLRs in immunity, inflammation, and associated diseases," Annual Review of Immunology, vol. 29, pp. 707-735, 2011.

[39] P. Matzinger, "Tolerance, danger, and the extended family," Annual Review of Immunology, vol. 12, pp. 9911045, 1994.

[40] J. Fan, R. S. Frey, and A. B. Malik, "TLR4 signaling induces TLR2 expression in endothelial cells via neutrophil NADPH oxidase," The Journal of Clinical Investigation, vol. 112, no. 8, pp. 1234-1243, 2003.

[41] J. Brown, H. Wang, G. N. Hajishengallis, and M. Martin, "TLR-signaling networks," Journal of Dental Research, vol. 90, no. 4, pp. 417-427, 2011.

[42] T. Lawrence, "The nuclear factor NF-kappaB pathway in inflammation," Cold Spring Harbor Perspectives in Biology, vol. 1, no. 6, article a001651, 2009.

[43] M. J. Morgan and Z. Liu, "Crosstalk of reactive oxygen species and NF- $\kappa$ B signaling," Cell Research, vol. 21, no. 1, pp. 103115, 2011.

[44] A. Abderrazak, T. Syrovets, D. Couchie et al., "NLRP3 inflammasome: from a danger signal sensor to a regulatory node of oxidative stress and inflammatory diseases," Redox Biology, vol. 4, pp. 296-307, 2015.

[45] M. L. Moss, S. L. Jin, M. E. Milla et al.et al., "Cloning of a disintegrin metalloproteinase that processes precursor tumour-necrosis factor-alpha," Nature, vol. 385, no. 6618, pp. 733-736, 1997.

[46] A. Chalaris, B. Rabe, K. Paliga et al., "Apoptosis is a natural stimulus of IL6R shedding and contributes to the proinflammatory trans-signaling function of neutrophils," Blood, vol. 110, no. 6, pp. 1748-1755, 2007.

[47] J. H. Bell, A. H. Herrera, Y. Li, and B. Walcheck, "Role of ADAM17 in the ectodomain shedding of TNF-alpha and its 
receptors by neutrophils and macrophages," Journal of Leukocyte Biology, vol. 82, no. 1, pp. 173-176, 2007.

[48] P. Ghezzi, "Protein glutathionylation in health and disease," Biochimica et Biophysica Acta (BBA) - General Subjects, vol. 1830, no. 5, pp. 3165-3172, 2013.

[49] L. Mullen, M. Seavill, R. Hammouz et al., "Development of 'redox arrays' for identifying novel glutathionylated proteins in the secretome," Scientific Reports, vol. 5, article 14630, 2015.

[50] P. Checconi, S. Salzano, L. Bowler et al., "Redox proteomics of the inflammatory secretome identifies a common set of redoxins and other glutathionylated proteins released in inflammation, influenza virus infection and oxidative stress," PLoS One, vol. 10, no. 5, article e0127086, 2015.

[51] L. Mullen, E.-M. Hanschmann, C. H. Lillig, L. A. Herzenberg, and P. Ghezzi, "Cysteine oxidation targets peroxiredoxins 1 and 2 for exosomal release through a novel mechanism of redox-dependent secretion," Molecular Medicine Cambridge, Mass, vol. 21, no. 1, pp. 98-108, 2015.

[52] S. Salzano, P. Checconi, E. M. Hanschmann et al., "Linkage of inflammation and oxidative stress via release of glutathionylated peroxiredoxin-2, which acts as a danger signal," Proceedings of the National Academy of Sciences of the United States of America, vol. 111, no. 33, pp. 12157-12162, 2014.

[53] Z. Yan, S. K. Garg, J. Kipnis, and R. Banerjee, "Extracellular redox modulation by regulatory $\mathrm{T}$ cells," Nature Chemical Biology, vol. 5, no. 10, pp. 721-723, 2009.

[54] L. Simeoni and I. Bogeski, "Redox regulation of T-cell receptor signaling," Biological Chemistry, vol. 396, no. 5, pp. 555568, 2015.

[55] G. Angelini, S. Gardella, M. Ardy et al., "Antigen-presenting dendritic cells provide the reducing extracellular microenvironment required for T lymphocyte activation," Proceedings of the National Academy of Sciences of the United States of America, vol. 99, no. 3, pp. 1491-1496, 2002.

[56] P. Castellani, G. Angelini, L. Delfino, A. Matucci, and A. Rubartelli, "The thiol redox state of lymphoid organs is modified by immunization: role of different immune cell populations," European Journal of Immunology, vol. 38, no. 9, pp. 2419-2425, 2008.

[57] J. P. Secrist, L. A. Burns, L. Karnitz, G. A. Koretzky, and R. T. Abraham, "Stimulatory effects of the protein tyrosine phosphatase inhibitor, pervanadate, on T-cell activation events," The Journal of Biological Chemistry, vol. 268, no. 8, pp. 5886-5893, 1993.

[58] M. Suthanthiran, M. E. Anderson, V. K. Sharma, and A. Meister, "Glutathione regulates activation-dependent DNA synthesis in highly purified normal human T lymphocytes stimulated via the CD2 and CD3 antigens," Proceedings of the National Academy of Sciences, vol. 87, no. 9, pp. 33433347, 1990.

[59] A. A. Hasan, A. M. Ghaemmaghami, L. Fairclough, A. Robins, H. F. Sewell, and F. Shakib, "Allergen-driven suppression of thiol production by human dendritic cells and the effect of thiols on T cell function," Immunobiology, vol. 214, no. 1, pp. 2-16, 2009.

[60] J. D. Peterson, L. A. Herzenberg, K. Vasquez, and C. Waltenbaugh, "Glutathione levels in antigen-presenting cells modulate Th1 versus Th2 response patterns," Proceedings of the National Academy of Sciences, vol. 95, no. 6, pp. 30713076, 1998.
[61] H. M. Tse, M. J. Milton, S. Schreiner, J. L. Profozich, M. Trucco, and J. D. Piganelli, "Disruption of innate-mediated proinflammatory cytokine and reactive oxygen species third signal leads to antigen-specific hyporesponsiveness," Journal of Immunology Baltimore, vol. 178, no. 2, pp. 908-917, 2007.

[62] T. Jikimoto, Y. Nishikubo, M. Koshiba et al., “Thioredoxin as a biomarker for oxidative stress in patients with rheumatoid arthritis," Molecular Immunology, vol. 38, no. 10, pp. 765$772,2002$.

[63] B. Adamczyk and M. Adamczyk-Sowa, "New insights into the role of oxidative stress mechanisms in the pathophysiology and treatment of multiple sclerosis," Oxidative Medicine and Cellular Longevity, vol. 2016, Article ID 1973834, 18 pages, 2016.

[64] L. Dai, A. Claxson, S. L. Marklund et al., "Amelioration of antigen-induced arthritis in rats by transfer of extracellular superoxide dismutase and catalase genes," Gene Therapy, vol. 10, no. 7, pp. 550-558, 2003.

[65] K. Kasarełło, A. Cudnoch-Jędrzejewska, A. Członkowski, and D. Mirowska-Guzel, "Mechanism of action of three newly registered drugs for multiple sclerosis treatment," Pharmacological Reports, vol. 69, no. 4, pp. 702-708, 2017.

[66] G. F. Wu and E. Alvarez, "The immunopathophysiology of multiple sclerosis," Neurologic Clinics, vol. 29, no. 2, pp. 257-278, 2011.

[67] H. R. Griffiths, "ROS as signalling molecules in T cells-evidence for abnormal redox signalling in the autoimmune disease, rheumatoid arthritis," Redox Report Communications Free Radical Research, vol. 10, no. 6, pp. 273-280, 2005.

[68] M. Ushio-Fukai, "Localizing NADPH oxidase-derived ROS," Sciences STKE Signal Transduction Knowledge Environment, vol. 2006, no. 349, article re8, 2006.

[69] A. Panday, M. K. Sahoo, D. Osorio, and S. Batra, "NADPH oxidases: an overview from structure to innate immunityassociated pathologies," Cellular \& Molecular Immunology, vol. 12, no. 1, pp. 5-23, 2015.

[70] S. Pendyala and V. Natarajan, "Redox regulation of Nox proteins," Respiratory Physiology \& Neurobiology, vol. 174, no. 3, pp. 265-271, 2010.

[71] P. Nunes, N. Demaurex, and M. C. Dinauer, "Regulation of the NADPH oxidase and associated ion fluxes during phagocytosis," Traffic, vol. 14, no. 11, pp. 1118-1131, 2013.

[72] R. Paletta-Silva, N. Rocco-Machado, and J. R. MeyerFernandes, "NADPH oxidase biology and the regulation of tyrosine kinase receptor signaling and cancer drug cytotoxicity," International Journal of Molecular Sciences, vol. 14, no. 2, pp. 3683-3704, 2013.

[73] F. D. Oakley, D. Abbott, Q. Li, and J. F. Engelhardt, "Signaling components of redox active endosomes: the redoxosomes," Antioxidants \& Redox Signaling, vol. 11, no. 6, pp. 13131333, 2009.

[74] N. Y. Spencer and J. F. Engelhardt, "The basic biology of redoxosomes in cytokine-mediated signal transduction and implications for disease-specific therapies," Biochemistry (Moscow), vol. 53, no. 10, pp. 1551-1564, 2014.

[75] F. J. Miller Jr., X. Chu, B. Stanic et al., "A differential role for endocytosis in receptor-mediated activation of Nox1," Antioxidants \& Redox Signaling, vol. 12, no. 5, pp. 583593, 2010. 
[76] Q. Li, M. M. Harraz, W. Zhou et al., "Nox2 and Rac1 regulate $\mathrm{H} 2 \mathrm{O} 2$-dependent recruitment of TRAF6 to endosomal interleukin-1 receptor complexes," Molecular and Cellular Biology, vol. 26, no. 1, pp. 140-154, 2006.

[77] F. D. Oakley, R. L. Smith, and J. F. Engelhardt, "Lipid rafts and caveolin-1 coordinate interleukin-1beta (IL-1beta)dependent activation of NFkappaB by controlling endocytosis of Nox 2 and IL-1beta receptor 1 from the plasma membrane," The Journal of Biological Chemistry, vol. 284, no. 48, pp. 33255-33264, 2009.

[78] T. Kawahara, Y. Kuwano, S. Teshima-Kondo et al., "Role of nicotinamide adenine dinucleotide phosphate oxidase 1 in oxidative burst response to Toll-like receptor 5 signaling in large intestinal epithelial cells," The Journal of Immunology, vol. 172, no. 5, pp. 3051-3058, 2004.

[79] S. Teshima, H. Kutsumi, T. Kawahara, K. Kishi, and K. Rokutan, "Regulation of growth and apoptosis of cultured guinea pig gastric mucosal cells by mitogenic oxidase 1," American Journal of Physiology - Gastrointestinal and Liver Physiology, vol. 279, no. 6, pp. G1169-G1176, 2000.

[80] J. G. Lee, S. H. Lee, D. W. Park et al., "Toll-like receptor 9stimulated monocyte chemoattractant protein-1 is mediated via JNK-cytosolic phospholipase $\mathrm{A}_{2}$-ROS signaling," Cellular Signalling, vol. 20, no. 1, pp. 105-111, 2008.

[81] M. Geiszt, J. B. Kopp, P. Várnai, and T. L. Leto, "Identification of renox, an NAD(P)H oxidase in kidney," Proceedings of the National Academy of Sciences of the United States of America, vol. 97, no. 14, pp. 8010-8014, 2000.

[82] S. Elsen, J. Doussière, C. L. Villiers et al., "Cryptic $\mathrm{O}_{2}^{-}$-generating NADPH oxidase in dendritic cells," Journal of Cell Science, vol. 117, Part 11, pp. 2215-2226, 2004.

[83] J. L. Koff, M. X. G. Shao, I. F. Ueki, and J. A. Nadel, "Multiple TLRs activate EGFR via a signaling cascade to produce innate immune responses in airway epithelium," American Journal of Physiology - Lung Cellular and Molecular Physiology, vol. 294, no. 6, pp. L1068-L1075, 2008.

[84] E. Ogier-Denis, S. B. Mkaddem, and A. Vandewalle, "NOX enzymes and Toll-like receptor signaling," Seminars in Immunopathology, vol. 30, no. 3, pp. 291-300, 2008.

[85] A. Savina, C. Jancic, S. Hugues et al., "NOX2 controls phagosomal $\mathrm{pH}$ to regulate antigen processing during crosspresentation by dendritic cells," Cell, vol. 126, no. 1, pp. 205-218, 2006.

[86] S. Chang, A. Linderholm, and R. Harper, "DUOX-mediated signaling is not required for LPS-induced neutrophilic response in the airways," PLoS One, vol. 10, no. 7, article e0131810, 2015.

[87] H. S. Park, J. N. Chun, H. Y. Jung, C. Choi, and Y. S. Bae, "Role of NADPH oxidase 4 in lipopolysaccharide-induced proinflammatory responses by human aortic endothelial cells," Cardiovascular Research, vol. 72, no. 3, pp. 447-455, 2006.

[88] E. Giannoni, F. Buricchi, G. Raugei, G. Ramponi, and P. Chiarugi, "Intracellular reactive oxygen species activate Src tyrosine kinase during cell adhesion and anchoragedependent cell growth," Molecular and Cellular Biology, vol. 25, no. 15, pp. 6391-6403, 2005.

[89] P. Chiarugi, "Src redox regulation: there is more than meets the eye," Molecules and Cells, vol. 26, no. 4, pp. 329337, 2008.

[90] C. E. Paulsen, T. H. Truong, F. J. Garcia et al., "Peroxidedependent sulfenylation of the EGFR catalytic site enhances kinase activity," Nature Chemical Biology, vol. 8, no. 1, pp. 57-64, 2011.

[91] D. E. Heppner, M. Hristova, C. M. Dustin, K. Danyal, A. Habibovic, and A. van der Vliet, "The NADPH oxidases DUOX1 and NOX2 play distinct roles in redox regulation of epidermal growth factor receptor signaling," The Journal of Biological Chemistry, vol. 291, no. 44, pp. 23282-23293, 2016.

[92] H. Sies, "Hydrogen peroxide as a central redox signaling molecule in physiological oxidative stress: oxidative eustress," Redox Biology, vol. 11, pp. 613-619, 2017.

[93] B. Stottmeier and T. P. Dick, "Redox sensitivity of the MyD88 immune signaling adapter," Free Radical Biology \& Medicine, vol. 101, pp. 93-101, 2016.

[94] T. Into, M. Inomata, M. Nakashima, K. Shibata, H. Häcker, and K. Matsushita, "Regulation of MyD88-dependent signaling events by $\mathrm{S}$ nitrosylation retards toll-like receptor signal transduction and initiation of acute-phase immune responses," Molecular and Cellular Biology, vol. 28, no. 4, pp. 1338-1347, 2008.

[95] A. Matsuzawa and H. Ichijo, "Redox control of cell fate by MAP kinase: physiological roles of ASK1-MAP kinase pathway in stress signaling," Biochimica et Biophysica Acta (BBA) General Subjects, vol. 1780, no. 11, pp. 1325-1336, 2008.

[96] J. J. Song and Y. J. Lee, "Differential role of glutaredoxin and thioredoxin in metabolic oxidative stress-induced activation of apoptosis signal-regulating kinase 1," The Biochemical Journal, vol. 373, Part 3, pp. 845-853, 2003.

[97] A. Matsuzawa, K. Saegusa, T. Noguchi et al., "ROS-dependent activation of the TRAF6-ASK1-p38 pathway is selectively required for TLR4-mediated innate immunity," Nature Immunology, vol. 6, no. 6, pp. 587-592, 2005.

[98] X. Guo, C. Harada, K. Namekata et al., "Regulation of the severity of neuroinflammation and demyelination by TLR-ASK1-p38 pathway," EMBO Molecular Medicine, vol. 2, no. 12, pp. 504-515, 2010.

[99] E. Pineda-Molina, P. Klatt, J. Vázquez et al., "Glutathionylation of the $\mathrm{p} 50$ subunit of NF- $\kappa \mathrm{B}$ : a mechanism for redoxinduced inhibition of DNA binding," Biochemistry, vol. 40, no. 47, pp. 14134-14142, 2001.

[100] D. Daily, A. Vlamis-Gardikas, D. Offen et al., "Glutaredoxin protects cerebellar granule neurons from dopamineinduced apoptosis by activating NF- $\kappa \mathrm{B}$ via Ref-1," Journal of Biological Chemistry, vol. 276, no. 2, pp. 1335-1344, 2001.

[101] K. Hirota, M. Matsui, M. Murata et al., "Nucleoredoxin, glutaredoxin, and thioredoxin differentially regulate NF- $\kappa \mathrm{B}, \mathrm{AP}-$ 1, and CREB activation in HEK293 cells," Biochemical and Biophysical Research Communications, vol. 274, no. 1, pp. 177-182, 2000.

[102] S. Witte, M. Villalba, K. Bi, Y. Liu, N. Isakov, and A. Altman, "Inhibition of the c-Jun N-terminal kinase/AP-1 and NF- $\kappa \mathrm{B}$ pathways by PICOT, a novel protein kinase C-interacting protein with a thioredoxin homology domain," The Journal of Biological Chemistry, vol. 275, no. 3, pp. 1902-1909, 2000.

[103] I. Rahman, J. Marwick, and P. Kirkham, "Redox modulation of chromatin remodeling: impact on histone acetylation and deacetylation, NF- $\kappa \mathrm{B}$ and pro-inflammatory gene expression," Biochemical Pharmacology, vol. 68, no. 6, pp. 12551267, 2004. 
[104] A. Nishiyama, M. Matsui, S. Iwata et al., "Identification of thioredoxin-binding protein-2/vitamin $\mathrm{D}_{3}$ up-regulated protein 1 as a negative regulator of thioredoxin function and expression," Journal of Biological Chemistry, vol. 274, no. 31, pp. 21645-21650, 1999.

[105] S. Rose-John, "IL-6 trans-signaling via the soluble IL-6 receptor: importance for the pro-inflammatory activities of IL-6," International Journal of Biological Sciences, vol. 8, no. 9, pp. 1237-1247, 2012.

[106] F. Schaper and S. Rose-John, "Interleukin-6: biology, signaling and strategies of blockade," Cytokine \& Growth Factor Reviews, vol. 26, no. 5, pp. 475-487, 2015.

[107] J. J. Peschon, J. L. Slack, P. Reddy et al., "An essential role for ectodomain shedding in mammalian development," Science, vol. 282, no. 5392, pp. 1281-1284, 1998.

[108] C. P. Blobel, "ADAMs: key components in EGFR signalling and development," Nature Reviews Molecular Cell Biology, vol. 6, no. 1, pp. 32-43, 2005.

[109] A. Chalaris, N. Adam, C. Sina et al., "Critical role of the disintegrin metalloprotease ADAM17 for intestinal inflammation and regeneration in mice," The Journal of Experimental Medicine, vol. 207, no. 8, pp. 1617-1624, 2010.

[110] M. A. West, A. R. Prescott, K. M. Chan et al., "TLR ligandinduced podosome disassembly in dendritic cells is ADAM17 dependent," The Journal of Cell Biology, vol. 182, no. 5, pp. 993-1005, 2008.

[111] R. S. Chanthaphavong, P. A. Loughran, T. Y. S. Lee, M. J. Scott, and T. R. Billiar, "A role for cGMP in inducible nitric-oxide synthase (iNOS)-induced tumor necrosis factor (TNF) $\alpha$-converting enzyme (TACE/ADAM17) activation, translocation, and TNF receptor 1 (TNFR1) shedding in hepatocytes," The Journal of Biological Chemistry, vol. 287, no. 43, pp. 35887-35898, 2012.

[112] A. Piccini, S. Carta, S. Tassi, D. Lasiglié, G. Fossati, and A. Rubartelli, "ATP is released by monocytes stimulated with pathogen-sensing receptor ligands and induces IL-1 $\beta$ and IL-18 secretion in an autocrine way," Proceedings of the National Academy of Sciences, vol. 105, no. 23, pp. 80678072, 2008.

[113] E. Asgari, G. Le Friec, H. Yamamoto et al., "C3a modulates IL- $1 \beta$ secretion in human monocytes by regulating ATP efflux and subsequent NLRP3 inflammasome activation," Blood, vol. 122, no. 20, pp. 3473-3481, 2013.

[114] A. W. Boots, M. Hristova, D. I. Kasahara, G. R. M. M. Haenen, A. Bast, and A. van der Vliet, "ATP-mediated activation of the NADPH oxidase DUOX1 mediates airway epithelial responses to bacterial stimuli," The Journal of Biological Chemistry, vol. 284, no. 26, pp. 17858-17867, 2009.

[115] D. Sham, U. V. Wesley, M. Hristova, and A. van der Vliet, "ATP-mediated transactivation of the epidermal growth factor receptor in airway epithelial cells involves DUOX1dependent oxidation of Src and ADAM17," PLoS One, vol. 8, no. 1, article e54391, 2013.

[116] H. Nakamura, K. Yoshimura, N. G. McElvaney, and R. G. Crystal, "Neutrophil elastase in respiratory epithelial lining fluid of individuals with cystic fibrosis induces interleukin-8 gene expression in a human bronchial epithelial cell line," The Journal of Clinical Investigation, vol. 89, no. 5, pp. 1478-1484, 1992.

[117] J. V. Fahy, K. W. Kim, J. Liu, and H. A. Boushey, "Prominent neutrophilic inflammation in sputum from subjects with asthma exacerbation," Journal of Allergy and Clinical Immunology, vol. 95, no. 4, pp. 843-852, 1995.

[118] M. X. G. Shao and J. A. Nadel, "Neutrophil elastase induces MUC5AC mucin production in human airway epithelial cells via a cascade involving protein kinase $C$, reactive oxygen species, and TNF- $\alpha$-converting enzyme," The Journal of Immunology, vol. 175, no. 6, pp. 4009-4016, 2005.

[119] M. X. G. Shao and J. A. Nadel, "Dual oxidase 1-dependent MUC5AC mucin expression in cultured human airway epithelial cells," Proceedings of the National Academy of Sciences of the United States of America, vol. 102, no. 3, pp. 767-772, 2005.

[120] I. Kuwahara, E. P. Lillehoj, T. Koga, Y. Isohama, T. Miyata, and K. C. Kim, "The signaling pathway involved in neutrophil elastase stimulated MUC1 transcription," American Journal of Respiratory Cell and Molecular Biology, vol. 37, no. 6, pp. 691-698, 2007.

[121] E. Thorp, T. Vaisar, M. Subramanian, L. Mautner, C. Blobel, and I. Tabas, "Shedding of the Mer tyrosine kinase receptor is mediated by ADAM17 protein through a pathway involving reactive oxygen species, protein kinase $C \delta$, and p38 mitogen-activated protein kinase (MAPK)," The Journal of Biological Chemistry, vol. 286, no. 38, pp. 3333533344, 2011.

[122] A. J. Scott, K. P. O'Dea, D. O'Callaghan et al., "Reactive oxygen species and p38 mitogen-activated protein kinase mediate tumor necrosis factor $\alpha$-converting enzyme (TACE/ADAM-17) activation in primary human monocytes," The Journal of Biological Chemistry, vol. 286, no. 41, pp. 35466-35476, 2011.

[123] J. Moreno-Càceres, J. Mainez, R. Mayoral, P. Martín-Sanz, G. Egea, and I. Fabregat, "Caveolin-1-dependent activation of the metalloprotease TACE/ADAM17 by TGF- $\beta$ in hepatocytes requires activation of Src and the NADPH oxidase NOX1," The FEBS Journal, vol. 283, no. 7, pp. 1300-1310, 2016.

[124] E. Tellier, M. Canault, L. Rebsomen et al., "The shedding activity of ADAM17 is sequestered in lipid rafts," Experimental Cell Research, vol. 312, no. 20, pp. 3969-3980, 2006.

[125] D. Shao, A. W. Segal, and L. V. Dekker, "Lipid rafts determine efficiency of NADPH oxidase activation in neutrophils," FEBS Letters, vol. 550, no. 1-3, pp. 101-106, 2003.

[126] F. Vilhardt and B. van Deurs, "The phagocyte NADPH oxidase depends on cholesterol-enriched membrane microdomains for assembly," The EMBO Journal, vol. 23, no. 4, pp. 739-748, 2004.

[127] H. P. Wang, X. Wang, L. F. Gong et al., "Nox1 promotes colon cancer cell metastasis via activation of the ADAM17 pathway," European Review for Medical and Pharmacological Sciences, vol. 20, no. 21, pp. 4474-4481, 2016.

[128] T. J. Myers, L. H. Brennaman, M. Stevenson et al., "Mitochondrial reactive oxygen species mediate GPCR-induced TACE/ADAM17-dependent transforming growth factor- $\alpha$ shedding," Molecular Biology of the Cell, vol. 20, no. 24, pp. 5236-5249, 2009.

[129] Y. Wang, J. D. Robertson, and B. Walcheck, "Different signaling pathways stimulate a disintegrin and metalloprotease-17 (ADAM17) in neutrophils during apoptosis and activation," The Journal of Biological Chemistry, vol. 286, no. 45, pp. 38980-38988, 2011.

[130] T. Maretzky, W. Zhou, X.-Y. Huang, and C. P. Blobel, “A transforming Src mutant increases the bioavailability of 
EGFR ligands via stimulation of the cell-surface metalloproteinase ADAM17," Oncogene, vol. 30, no. 5, pp. 611-618, 2011.

[131] S. Van Schaeybroeck, D. M. Kelly, J. Kyula et al., "Src and ADAM-17-mediated shedding of transforming growth factor-alpha is a mechanism of acute resistance to TRAIL," Cancer Research, vol. 68, no. 20, pp. 8312-8321, 2008.

[132] P. Xu and R. Derynck, "Direct activation of TACE-mediated ectodomain shedding by p38 MAP kinase regulates EGF receptor-dependent cell proliferation," Molecular Cell, vol. 37, no. 4, pp. 551-566, 2010.

[133] S. M. Soond, B. Everson, D. W. H. Riches, and G. Murphy, "ERK-mediated phosphorylation of Thr735 in TNF $\alpha$ converting enzyme and its potential role in TACE protein trafficking," Journal of Cell Science, vol. 118, Part 11, pp. 2371-2380, 2005.

[134] P. W. Janes, N. Saha, W. A. Barton et al., “Adam meets Eph: an ADAM substrate recognition module acts as a molecular switch for ephrin cleavage in trans," Cell, vol. 123, no. 2, pp. 291-304, 2005.

[135] S. Düsterhöft, S. Jung, C. W. Hung et al., "Membraneproximal domain of a disintegrin and metalloprotease-17 represents the putative molecular switch of its shedding activity operated by protein-disulfide isomerase," Journal of the American Chemical Society, vol. 135, no. 15, pp. 5776-5781, 2013.

[136] S. Takeda, "Three-dimensional domain architecture of the ADAM family proteinases," Seminars in Cell \& Developmental Biology, vol. 20, no. 2, pp. 146-152, 2009.

[137] S. Düsterhöft, K. Höbel, M. Oldefest et al., “A disintegrin and metalloprotease 17 dynamic interaction sequence, the sweet tooth for the human interleukin 6 receptor," The Journal of Biological Chemistry, vol. 289, no. 23, pp. $16336-$ 16348, 2014.

[138] Y. Wang, A. H. Herrera, Y. Li, K. K. Belani, and B. Walcheck, "Regulation of mature ADAM17 by redox agents for Lselectin shedding," Journal of Immunology, vol. 182, no. 4, pp. 2449-2457, 2009.

[139] S. Düsterhöft, M. Michalek, F. Kordowski et al., "Extracellular juxtamembrane segment of ADAM17 interacts with membranes and is essential for its shedding activity," Biochemistry (Moscow), vol. 54, no. 38, pp. 5791-5801, 2015.

[140] A. Sommer, F. Kordowski, J. Büch et al., "Phosphatidylserine exposure is required for ADAM17 sheddase function," Nature Communications, vol. 7, article 11523, 2016.

[141] T. W. Kim, H. H. Ryu, S. Y. Li et al., "PDIA6 regulation of ADAM17 shedding activity and EGFR-mediated migration and invasion of glioblastoma cells," Journal of Neurosurgery, vol. 126, no. 6, pp. 1829-1838, 2017.

[142] Y. Liu, W. Hao, A. Dawson, S. Liu, and K. Fassbender, "Expression of amyotrophic lateral sclerosis-linked SOD1 mutant increases the neurotoxic potential of microglia via TLR2," The Journal of Biological Chemistry, vol. 284, no. 6, pp. 3691-3699, 2009.

[143] M. P. Sanderson, C. A. Abbott, H. Tada, M. Seno, P. J. Dempsey, and A. J. Dunbar, "Hydrogen peroxide and endothelin-1 are novel activators of betacellulin ectodomain shedding," Journal of Cellular Biochemistry, vol. 99, no. 2, pp. 609-623, 2006.

[144] U. Schwertassek, Y. Balmer, M. Gutscher et al., "Selective redox regulation of cytokine receptor signaling by extracellular thioredoxin-1," The EMBO Journal, vol. 26, no. 13, pp. 3086-3097, 2007.

[145] P. A. Jordan and J. M. Gibbins, "Extracellular disulfide exchange and the regulation of cellular function," Antioxidants \& Redox Signaling, vol. 8, no. 3-4, pp. 312-324, 2006.

[146] J. Li, R. Kokkola, S. Tabibzadeh et al., "Structural basis for the proinflammatory cytokine activity of high mobility group box 1," Molecular Medicine, vol. 9, no. 1-2, pp. 3745, 2003.

[147] H. Yang, H. Wang, S. S. Chavan, and U. Andersson, "High mobility group box protein 1 (HMGB1): the prototypical endogenous danger molecule," Molecular Medicine, vol. 21, Supplement 1, pp. S6-S12, 2015.

[148] S. Gardella, C. Andrei, D. Ferrera et al., "The nuclear protein HMGB1 is secreted by monocytes via a non-classical, vesiclemediated secretory pathway," EMBO Reports, vol. 3, no. 10, pp. 995-1001, 2002.

[149] K. Kawahara, T. Hashiguchi, K. Masuda et al., "Mechanism of HMGB1 release inhibition from RAW264.7 cells by oleanolic acid in Prunus mume Sieb. et Zucc," International Journal of Molecular Medicine, vol. 23, no. 5, pp. 615-620, 2009.

[150] P. Scaffidi, T. Misteli, and M. E. Bianchi, "Release of chromatin protein HMGB1 by necrotic cells triggers inflammation," Nature, vol. 418, no. 6894, pp. 191-195, 2002.

[151] C. Janko, M. Filipović, L. E. Munoz et al., "Redox modulation of HMGB1-related signaling," Antioxidants \& Redox Signaling, vol. 20, no. 7, pp. 1075-1085, 2014.

[152] D. Tang, R. Kang, K. M. Livesey, H. J. Zeh, and M. T. Lotze, "High mobility group box 1 (HMGB1) activates an autophagic response to oxidative stress," Antioxidants \& Redox Signaling, vol. 15, no. 8, pp. 2185-2195, 2011.

[153] G. Hoppe, K. E. Talcott, S. K. Bhattacharya, J. W. Crabb, and J. E. Sears, "Molecular basis for the redox control of nuclear transport of the structural chromatin protein Hmgb1," Experimental Cell Research, vol. 312, no. 18, pp. 3526-3538, 2006.

[154] H. Yang, H. S. Hreggvidsdottir, K. Palmblad et al., "A critical cysteine is required for HMGB1 binding to Toll-like receptor 4 and activation of macrophage cytokine release," Proceedings of the National Academy of Sciences of the United States of America, vol. 107, no. 26, pp. 11942-11947, 2010.

[155] H. Yang, P. Lundbäck, L. Ottosson et al., "Redox modification of cysteine residues regulates the cytokine activity of high mobility group box-1 (HMGB1)," Molecular Medicine, vol. 18, pp. 250-259, 2012.

[156] E. Venereau, M. Casalgrandi, M. Schiraldi et al., "Mutually exclusive redox forms of HMGB1 promote cell recruitment or proinflammatory cytokine release," The Journal of Experimental Medicine, vol. 209, no. 9, pp. 1519-1528, 2012.

[157] H. Yang, D. J. Antoine, U. Andersson, and K. J. Tracey, "The many faces of HMGB1: molecular structure-functional activity in inflammation, apoptosis, and chemotaxis," Journal of Leukocyte Biology, vol. 93, no. 6, pp. 865-873, 2013.

[158] D. Sahu, P. Debnath, Y. Takayama, and J. Iwahara, "Redox properties of the A-domain of the HMGB1 protein," FEBS Letters, vol. 582, no. 29, pp. 3973-3978, 2008.

[159] Y. Tagaya, Y. Maeda, A. Mitsui et al., "ATL-derived factor (ADF), an IL-2 receptor/Tac inducer homologous to thioredoxin; possible involvement of dithiol-reduction in the IL-2 receptor induction," The EMBO Journal, vol. 8, no. 3, pp. 757-764, 1989. 
[160] H. Schenk, M. Vogt, W. Dröge, and K. Schulze-Osthoff, "Thioredoxin as a potent costimulus of cytokine expression," Journal of Immunology, vol. 156, no. 2, pp. 765-771, 1996.

[161] K. Pekkari and A. Holmgren, "Truncated thioredoxin: physiological functions and mechanism," Antioxidants \& Redox Signaling, vol. 6, no. 1, pp. 53-61, 2004.

[162] A. Son, N. Kato, T. Horibe et al., "Direct association of thioredoxin-1 (TRX) with macrophage migration inhibitory factor (MIF): regulatory role of TRX on MIF internalization and signaling," Antioxidants \& Redox Signaling, vol. 11, no. 10, pp. 2595-2605, 2009.

[163] W. M. Nauseef, "Neutrophils, from cradle to grave and beyond," Immunological Reviews, vol. 273, no. 1, pp. 5-10, 2016.

[164] The resurrection of myeloperoxidase as a therapeutic target | JACC: basic to translational science," 2017, http://www. basictranslational.onlinejacc.org/content/1/7/644.

[165] J. Olza, C. M. Aguilera, M. Gil-Campos et al., "Myeloperoxidase is an early biomarker of inflammation and cardiovascular risk in prepubertal obese children," Diabetes Care, vol. 35, no. 11, pp. 2373-2376, 2012.

[166] R. K. Schindhelm, L. P. van der Zwan, T. Teerlink, and P. G. Scheffer, "Myeloperoxidase: a useful biomarker for cardiovascular disease risk stratification?," Clinical Chemistry, vol. 55, no. 8, pp. 1462-1470, 2009.

[167] A. Daugherty, J. L. Dunn, D. L. Rateri, and J. W. Heinecke, "Myeloperoxidase, a catalyst for lipoprotein oxidation, is expressed in human atherosclerotic lesions," The Journal of Clinical Investigation, vol. 94, no. 1, pp. 437-444, 1994.

[168] L. K. Stamp, I. Khalilova, J. M. Tarr et al., "Myeloperoxidase and oxidative stress in rheumatoid arthritis," Rheumatology, vol. 51, no. 10, pp. 1796-1803, 2012.

[169] C. Sinning, R. Schnabel, W. F. Peacock, and S. Blankenberg, "Up-and-coming markers: myeloperoxidase, a novel biomarker test for heart failure and acute coronary syndrome application?," Congestive Heart Failure, vol. 14, no. 4, Supplement 1, pp. 46-48, 2008.

[170] I. H. Buss, R. Senthilmohan, B. A. Darlow, N. Mogridge, A. J. Kettle, and C. C. Winterbourn, "3-Chlorotyrosine as a marker of protein damage by myeloperoxidase in tracheal aspirates from preterm infants: association with adverse respiratory outcome," Pediatric Research, vol. 53, no. 3, pp. 455-462, 2003.

[171] A. J. Kettle and C. C. Winterbourn, "Mechanism of inhibition of myeloperoxidase by anti-inflammatory drugs," Biochemical Pharmacology, vol. 41, no. 10, pp. 1485-1492, 1991.

[172] A. Jucaite, P. Svenningsson, J. O. Rinne et al., "Effect of the myeloperoxidase inhibitor AZD3241 on microglia: a PET study in Parkinson's disease," Brain: A Journal of Neurology, vol. 138, Part 9, pp. 2687-2700, 2015.

[173] L. V. Forbes, T. Sjögren, F. Auchère et al., "Potent reversible inhibition of myeloperoxidase by aromatic hydroxamates," The Journal of Biological Chemistry, vol. 288, no. 51, pp. 36636-36647, 2013.

[174] H. Parker, A. M. Albrett, A. J. Kettle, and C. C. Winterbourn, "Myeloperoxidase associated with neutrophil extracellular traps is active and mediates bacterial killing in the presence of hydrogen peroxide," Journal of Leukocyte Biology, vol. 91, no. 3, pp. 369-376, 2012.

[175] B. Pinegin, N. Vorobjeva, and V. Pinegin, "Neutrophil extracellular traps and their role in the development of chronic inflammation and autoimmunity," Autoimmunity Reviews, vol. 14, no. 7, pp. 633-640, 2015.

[176] P. S. Green, A. J. Mendez, J. S. Jacob et al., "Neuronal expression of myeloperoxidase is increased in Alzheimer's disease," Journal of Neurochemistry, vol. 90, no. 3, pp. 724-733, 2004.

[177] C. B. Ambrosone, W. E. Barlow, W. Reynolds et al., "Myeloperoxidase genotypes and enhanced efficacy of chemotherapy for early-stage breast cancer in SWOG-8897," Journal of Clinical Oncology: Official Journal of the American Society of Clinical Oncology, vol. 27, no. 30, pp. 4973-4979, 2009.

[178] P. G. Furtmüller, W. Jantschko, G. Regelsberger, C. Jakopitsch, J. Arnhold, and C. Obinger, "Reaction of lactoperoxidase compound I with halides and thiocyanate," Biochemistry, vol. 41, no. 39, pp. 11895-11900, 2002.

[179] E. Shimizu, T. Kobayashi, H. Wakabayashi, K. Yamauchi, K. Iwatsuki, and H. Yoshie, "Effects of orally administered lactoferrin and lactoperoxidase-containing tablets on clinical and bacteriological profiles in chronic periodontitis patients," International Journal Dentistry, vol. 2011, Article ID 405139, 9 pages, 2011.

[180] Y. Güven, I. Satman, N. Dinççağ, and S. Alptekin, "Salivary peroxidase activity in whole saliva of patients with insulindependent (type-1) diabetes mellitus," Journal of Clinical Periodontology, vol. 23, no. 9, pp. 879-881, 1996.

[181] C. V. Kalburgi, K. L. Naik, M. V. Kokatnur, and S. Warad, "Estimation and correlation of salivary thiocyanate levels in healthy and different forms of tobacco users having chronic periodontitis: a cross-sectional biochemical study," Contemporary Clinical Dentistry, vol. 5, no. 2, pp. 182-186, 2014.

[182] K. Cherubini, C. S. Lorandi, S. M. Krapf et al., “Association between recurrent aphthous stomatitis and salivary thiocyanate levels," Journal of Oral Science, vol. 48, no. 3, pp. 153156, 2006.

[183] G. C. Kiran and B. A. Reginald, "Aphthous ulcers, salivary peroxidase and stress: are they related?," Journal of Oral Maxillofacial Pathology, vol. 19, no. 1, pp. 37-41, 2015.

[184] J. Flemmig, D. Rusch, M. E. Czerwińska, H.-W. Rauwald, and J. Arnhold, "Components of a standardised olive leaf dry extract (Ph. Eur.) promote hypothiocyanite production by lactoperoxidase," Archives of Biochemistry and Biophysics, vol. 549, pp. 17-25, 2014.

[185] T. Bundgaard, J. Wildt, M. Frydenberg, O. Elbrønd, and J. E. Nielsen, "Case-control study of squamous cell cancer of the oral cavity in Denmark," Cancer Causes Control, vol. 6, no. 1, pp. 57-67, 1995.

[186] R. V. Luepker, T. F. Pechacek, D. M. Murray, C. A. Johnson, F. Hund, and D. R. Jacobs, "Saliva thiocyanate: a chemical indicator of cigarette smoking in adolescents," American Journal of Public Health, vol. 71, no. 12, pp. 1320-1324, 1981.

[187] A. Z. Reznick, I. Klein, J. P. Eiserich, C. E. Cross, and R. M. Nagler, "Inhibition of oral peroxidase activity by cigarette smoke: in vivo and in vitro studies," Free Radical Biology \& Medicine, vol. 34, no. 3, pp. 377-384, 2003.

[188] E. B. de Oliveira-Junior, J. Bustamante, P. E. Newburger, and A. Condino-Neto, "The human NADPH oxidase: primary and secondary defects impairing the respiratory burst function and the microbicidal ability of phagocytes," Scandinavian Journal of Immunology, vol. 73, no. 5, pp. 420-427, 2011.

[189] D. B. Kuhns, W. G. Alvord, T. Heller et al., "Residual NADPH oxidase and survival in chronic granulomatous 
disease," The New England Journal of Medicine, vol. 363, no. 27, pp. 2600-2610, 2010.

[190] L. A. Allen, F. R. DeLeo, A. Gallois, S. Toyoshima, K. Suzuki, and W. M. Nauseef, "Transient association of the nicotinamide adenine dinucleotide phosphate oxidase subunits p47phox and p67phox with phagosomes in neutrophils from patients with X-linked chronic granulomatous disease," Blood, vol. 93, no. 10, pp. 3521-3530, 1999.

[191] I. Takac, K. Schröder, and R. P. Brandes, “The Nox family of NADPH oxidases: friend or foe of the vascular system?," Current Hypertension Reports, vol. 14, no. 1, pp. 70-78, 2012.

[192] P. A. Krijnen, C. Meischl, C. E. Hack et al., "Increased Nox2 expression in human cardiomyocytes after acute myocardial infarction," Journal of Clinical Pathology, vol. 56, no. 3, pp. 194-199, 2003.

[193] C. Heymes, J. K. Bendall, P. Ratajczak et al., "Increased myocardial NADPH oxidase activity in human heart failure," Journal of the American College of Cardiology, vol. 41, no. 12 , pp. 2164-2171, 2003.

[194] R. Dworakowski, S. Walker, A. Momin et al., "Reduced nicotinamide adenine dinucleotide phosphate oxidase-derived superoxide and vascular endothelial dysfunction in human heart failure," Journal of the American College of Cardiology, vol. 51, no. 14, pp. 1349-1356, 2008.

[195] T. J. Guzik, N. E. West, E. Black et al., "Vascular superoxide production by $\mathrm{NAD}(\mathrm{P}) \mathrm{H}$ oxidase: association with endothelial dysfunction and clinical risk factors," Circulation Research, vol. 86, no. 9, pp. E85-E90, 2000.

[196] J. Streeter, W. Thiel, K. Brieger, and F. J. Miller, “Opportunity Nox: the future of NADPH oxidases as therapeutic targets in cardiovascular disease," Cardiovascular Therapeutics, vol. 31, no. 3, pp. 125-137, 2013.

[197] C. Berry, C. A. Hamilton, M. J. Brosnan et al., "Investigation into the sources of superoxide in human blood vessels: angiotensin II increases superoxide production in human internal mammary arteries," Circulation, vol. 101, no. 18, pp. 22062212, 2000.

[198] B. Guzik, M. Chwała, P. Matusik et al., "Mechanisms of increased vascular superoxide production in human varicose veins," Polskie Archiwum Medycyny Wewnętrznej, vol. 121, no. 9, pp. 279-286, 2011.

[199] Y. Gorin and K. Block, "Nox as a target for diabetic complications," Clinical Science, vol. 125, no. 8, pp. 361-382, 2013.

[200] J.-J. Peng, B. Liu, J.-Y. Xu, J. Peng, and X.-J. Luo, "NADPH oxidase: its potential role in promotion of pulmonary arterial hypertension," Naunyn-Schmiedeberg's Archives of Pharmacology, vol. 390, no. 4, pp. 331-338, 2017.

[201] F. Liu-Smith, R. Dellinger, and F. L. Meyskens, "Updates of reactive oxygen species in melanoma etiology and progression," Archives of Biochemistry and Biophysics, vol. 563, pp. 51-55, 2014.

[202] W. H. Yin, P. Chen, H. I. Yeh et al., "Combination with low-dose dextromethorphan improves the effect of amlodipine monotherapy in clinical hypertension: a first-in-human, concept-proven, prospective, dose-escalation, multicenter study," Medicine (Baltimore), vol. 95, no. 12, article e3234, 2016.

[203] J. L. Meitzler, S. Antony, Y. Wu et al., "NADPH oxidases: a perspective on reactive oxygen species production in tumor biology," Antioxidants \& Redox Signaling, vol. 20, no. 17 , pp. 2873-2889, 2014.
[204] M. Ushio-Fukai and Y. Nakamura, "Reactive oxygen species and angiogenesis: NADPH oxidase as target for cancer therapy," Cancer Letters, vol. 266, no. 1, pp. 37-52, 2008.

[205] J. L. Arbiser, M. Bips, A. Seidler, M. Y. Bonner, and C. Kovach, "Combination therapy of imiquimod and gentian violet for cutaneous melanoma metastases," Journal of the American Academy of Dermatology, vol. 67, no. 2, pp. e81-e83, 2012.

[206] R. K. Murthy, L. Van, and J. L. Arbiser, "Treatment of extensive erythema multiforme with topical gentian violet," Experimental Dermatology, vol. 26, no. 5, pp. 431-432, 2017.

[207] S. R. Tannenbaum, D. Fett, V. R. Young, P. D. Land, and W. R. Bruce, "Nitrite and nitrate are formed by endogenous synthesis in the human intestine," Science, vol. 200, no. 4349, pp. 1487-1489, 1978.

[208] C. Bogdan, "Nitric oxide and the immune response," Nature Immunology, vol. 2, no. 10, pp. 907-916, 2001.

[209] K. A. Kirkebøen and O. A. Strand, "The role of nitric oxide in sepsis-an overview," Acta Anaesthesiologica Scandinavica, vol. 43, no. 3, pp. 275-288, 1999.

[210] S. R. Jaffrey and S. H. Snyder, "Nitric oxide: a neural messenger," Annual Review of Cell and Developmental Biology, vol. 11, pp. 417-440, 1995.

[211] H. Kleinert, C. Euchenhofer, I. Ihrig-Biedert, and U. Förstermann, "Glucocorticoids inhibit the induction of nitric oxide synthase II by down-regulating cytokine-induced activity of transcription factor nuclear factor-kappa B," Molecular Pharmacology, vol. 49, no. 1, pp. 15-21, 1996.

[212] M. A. Titheradge, "Nitric oxide in septic shock," Biochimica et Biophysica Acta (BBA) - Bioenergetics, vol. 1411, no. 2-3, pp. 437-455, 1999.

[213] B. E. Kreger, D. E. Craven, and W. R. McCabe, "Gram-negative bacteremia. IV. Re-evaluation of clinical features and treatment in 612 patients," The American Journal of Medicine, vol. 68, no. 3, pp. 344-355, 1980.

[214] J. H. Christy, "Treatment of gram-negative shock," The American Journal of Medicine, vol. 50, no. 1, pp. 77-88, 1971.

[215] C. L. Sprung, P. V. Caralis, E. H. Marcial et al., "The effects of high-dose corticosteroids in patients with septic shock. A prospective, controlled study," The New England Journal of Medicine, vol. 311, no. 18, pp. 1137-1143, 1984.

[216] B. Gachot, J. P. Bedos, B. Veber, M. Wolff, and B. Regnier, "Short-term effects of methylene blue on hemodynamics and gas exchange in humans with septic shock," Intensive Care Medicine, vol. 21, no. 12, pp. 1027-1031, 1995.

[217] J. M. Fukuto, K. S. Wood, R. E. Byrns, and L. J. Ignarro, "NGamino-L-arginine: a new potent antagonist of L-argininemediated endothelium-dependent relaxation," Biochemical and Biophysical Research Communications, vol. 168, no. 2, pp. 458-465, 1990.

[218] A. Petros, D. Bennett, and P. Vallance, "Effect of nitric oxide synthase inhibitors on hypotension in patients with septic shock," The Lancet, vol. 338, no. 8782-8783, pp. 1557-1558, 1991.

[219] A. López, J. A. Lorente, J. Steingrub et al., "Multiple-center, randomized, placebo-controlled, double-blind study of the nitric oxide synthase inhibitor 546C88: effect on survival in patients with septic shock," Critical Care Medicine, vol. 32, no. 1, pp. 21-30, 2004.

[220] L. H. Lassen, M. Ashina, I. Christiansen et al., "Nitric oxide synthase inhibition: a new principle in the treatment of migraine attacks," Cephalalgia, vol. 18, no. 1, pp. 27-32, 1998. 
[221] J. Palmer, F. Guillard, B. Laurijssens, A. Wentz, R. Dixon, and P. Williams, "A randomised, single-blind, placebo-controlled, adaptive clinical trial of gw274150, a selective iNOS inhibitor, in the treatment of acute migraine," Cephalalgia, vol. 29, no. 1, p. 124, 2009.

[222] H. O. Høivik, B. E. Laurijssens, L. O. Harnisch et al., "Lack of efficacy of the selective iNOS inhibitor GW274150 in prophylaxis of migraine headache," Cephalalgia, vol. 30, no. 12, pp. 1458-1467, 2010.

[223] M. E. Wechsler, H. Grasemann, A. Deykin et al., "Exhaled nitric oxide in patients with asthma: association with NOS1 genotype," American Journal of Respiratory and Critical Care Medicine, vol. 162, no. 6, pp. 2043-2047, 2000.

[224] T. T. Hansel, S. A. Kharitonov, L. E. Donnelly et al., "A selective inhibitor of inducible nitric oxide synthase inhibits exhaled breath nitric oxide in healthy volunteers and asthmatics," FASEB Journal, vol. 17, no. 10, pp. 12981300, 2003.

[225] D. Singh, D. Richards, R. G. Knowles et al., "Selective inducible nitric oxide synthase inhibition has no effect on allergen challenge in asthma," American Journal of Respiratory and Critical Care Medicine, vol. 176, no. 10, pp. 988-993, 2007.

[226] F. L. Ricciardolo, P. Geppetti, A. Mistretta et al., "Randomised double-blind placebo-controlled study of the effect of inhibition of nitric oxide synthesis in bradykinin-induced asthma," The Lancet, vol. 348, no. 9024, pp. 374-377, 1996.

[227] M. Seymour, F. Pétavy, F. Chiesa et al., "Ultrasonographic measures of synovitis in an early phase clinical trial: a double-blind, randomised, placebo and comparator controlled phase IIa trial of GW274150 (a selective inducible nitric oxide synthase inhibitor) in rheumatoid arthritis," Clinical and Experimental Rheumatology, vol. 30, no. 2, pp. 254-261, 2012.

[228] P. Pacher, J. S. Beckman, and L. Liaudet, "Nitric oxide and peroxynitrite in health and disease," Physiological Reviews, vol. 87, no. 1, pp. 315-424, 2007.

[229] C. S. Baker, D. P. Dutka, D. Pagano et al., "Immunocytochemical evidence for inducible nitric oxide synthase and cyclooxygenase- 2 expression with nitrotyrosine formation in human hibernating myocardium," Basic Research in Cardiology, vol. 97, no. 5, pp. 409-415, 2002.

[230] S. Ravalli, A. Albala, M. Ming et al., "Inducible nitric oxide synthase expression in smooth muscle cells and macrophages of human transplant coronary artery disease," Circulation, vol. 97, no. 23, pp. 2338-2345, 1998.

[231] M. J. Szabolcs, S. Ravalli, O. Minanov, R. R. Sciacca, R. E. Michler, and P. J. Cannon, "Apoptosis and increased expression of inducible nitric oxide synthase in human allograft rejection," Transplantation, vol. 65, no. 6, pp. 804-812, 1998.

[232] G. A. Haywood, P. S. Tsao, H. E. von der Leyen et al., "Expression of inducible nitric oxide synthase in human heart failure," Circulation, vol. 93, no. 6, pp. 1087-1094, 1996.

[233] S. Ekmekcioglu, J. Ellerhorst, C. M. Smid et al., "Inducible nitric oxide synthase and nitrotyrosine in human metastatic melanoma tumors correlate with poor survival," Clinical Cancer Research, vol. 6, no. 12, pp. 4768-4775, 2000.

[234] M. Vakkala, K. Kahlos, E. Lakari, P. Pääkkö, V. Kinnula, and Y. Soini, "Inducible nitric oxide synthase expression, apoptosis, and angiogenesis in in situ and invasive breast carcinomas," Clinical Cancer Research, vol. 6, no. 6, pp. 2408-2416, 2000.
[235] M. J. Pukkila, J. K. Kellokoski, J. A. Virtaniemi et al., "Inducible nitric oxide synthase expression in pharyngeal squamous cell carcinoma: relation to p53 expression, clinicopathological data, and survival," The Laryngoscope, vol. 112, no. 6, pp. 1084-1088, 2002.

[236] B. Halliwell, "Free radicals, reactive oxygen species and human disease: a critical evaluation with special reference to atherosclerosis," British Journal of Experimental Pathology, vol. 70, no. 6, pp. 737-757, 1989.

[237] F. Zipp and O. Aktas, "The brain as a target of inflammation: common pathways link inflammatory and neurodegenerative diseases," Trends in Neurosciences, vol. 29, no. 9, pp. 518-527, 2006.

[238] T. A. Sarafian, M. A. Verity, H. V. Vinters et al., "Differential expression of peroxiredoxin subtypes in human brain cell types," Journal of Neuroscience Research, vol. 56, no. 2, pp. 206-212, 1999.

[239] H. Mizusawa, T. Ishii, and S. Bannai, "Peroxiredoxin I (macrophage $23 \mathrm{kDa}$ stress protein) is highly and widely expressed in the rat nervous system," Neuroscience Letters, vol. 283, no. 1, pp. 57-60, 2000.

[240] S. Kato, M. Kato, Y. Abe et al., "Redox system expression in the motor neurons in amyotrophic lateral sclerosis (ALS): immunohistochemical studies on sporadic ALS, superoxide dismutase 1 (SOD1)-mutated familial ALS, and SOD1mutated ALS animal models," Acta Neuropatholica, vol. 110, no. 2, pp. 101-112, 2005.

[241] R. C. Cumming, R. Dargusch, W. H. Fischer, and D. Schubert, "Increase in expression levels and resistance to sulfhydryl oxidation of peroxiredoxin isoforms in amyloid betaresistant nerve cells," The Journal of Biological Chemistry, vol. 282, no. 42, pp. 30523-30534, 2007.

[242] K. Krapfenbauer, E. Engidawork, N. Cairns, M. Fountoulakis, and G. Lubec, "Aberrant expression of peroxiredoxin subtypes in neurodegenerative disorders," Brain Research, vol. 967, no. 1-2, pp. 152-160, 2003.

[243] Y. Yoshida, A. Yoshikawa, T. Kinumi et al., "Hydroxyoctadecadienoic acid and oxidatively modified peroxiredoxins in the blood of Alzheimer's disease patients and their potential as biomarkers," Neurobiology of Aging, vol. 30, no. 2, pp. 174185, 2009.

[244] J. Fang, T. Nakamura, D.-H. Cho, Z. Gu, and S. A. Lipton, "S-nitrosylation of peroxiredoxin 2 promotes oxidative stress-induced neuronal cell death in Parkinson's disease," Proceedings of the National Academy of Sciences of the United States of America, vol. 104, no. 47, pp. 1874218747, 2007.

[245] D. Qu, J. Rashidian, M. P. Mount et al., "Role of Cdk5mediated phosphorylation of Prx2 in MPTP toxicity and Parkinson's disease," Neuron, vol. 55, no. 1, pp. 37-52, 2007.

[246] M. Basso, S. Giraudo, D. Corpillo, B. Bergamasco, L. Lopiano, and M. Fasano, "Proteome analysis of human substantia nigra in Parkinson's disease," Proteomics, vol. 4, no. 12, pp. 39433952, 2004.

[247] D. Butterfield, R. Sultana, and H. Poon, "Redox proteomics: a new approach to investigate oxidative stress in Alzheimer's disease," in Neurodegenerative Disorders, Aging and Antioxidants, Marcel Dekker Inc, New York, NY, USA, 2006.

[248] S. H. Kim, M. Fountoulakis, N. Cairns, and G. Lubec, "Protein levels of human peroxiredoxin subtypes in brains of patients with Alzheimer's disease and Down syndrome," 
Journal of Neural Transmission Supplementum, no. 61, pp. 223-235, 2001.

[249] N. Fatma, E. Kubo, C. B. Toris, W. D. Stamer, C. B. Camras, and D. P. Singh, "PRDX6 attenuates oxidative stress- and TGFbeta-induced abnormalities of human trabecular meshwork cells," Free Radical Research, vol. 43, no. 9, pp. 783795, 2009.

[250] N. Hasanova, E. Kubo, Y. Kumamoto, Y. Takamura, and Y. Akagi, "Age-related cataracts and Prdx6: correlation between severity of lens opacity, age and the level of Prdx 6 expression," The British Journal of Ophthalmology, vol. 93, no. 8, pp. 1081-1084, 2009.

[251] B.-B. Gao, X. Chen, N. Timothy, L. P. Aiello, and E. P. Feener, "Characterization of the vitreous proteome in diabetes without diabetic retinopathy and diabetes with proliferative diabetic retinopathy," Journal of Proteome Research, vol. 7, no. 6, pp. 2516-2525, 2008.

[252] A. Abbasi, E. Corpeleijn, R. T. Gansevoort et al., "Circulating peroxiredoxin 4 and type 2 diabetes risk: the prevention of renal and vascular endstage disease (PREVEND) study," Diabetologia, vol. 57, no. 9, pp. 1842-1849, 2014.

[253] S. F. Moss and M. J. Blaser, "Mechanisms of disease: inflammation and the origins of cancer," Nature Clinical Practice Oncology, vol. 2, no. 2, pp. 90-97, 2005, quiz 1 $\mathrm{p}$ following 113.

[254] Y. S. Kim, H. L. Lee, K. B. Lee et al., "Nuclear factor E2-related factor 2 dependent overexpression of sulfiredoxin and peroxiredoxin III in human lung cancer," The Korean Journal of Internal Medicine, vol. 26, no. 3, pp. 304-313, 2011.

[255] J. W. Chang, S. H. Lee, J. Y. Jeong et al., "Peroxiredoxin-I is an autoimmunogenic tumor antigen in non-small cell lung cancer," FEBS Letters, vol. 579, no. 13, pp. 2873-2877, 2005.

[256] Y. W. Xu, Y. H. Peng, B. Chen et al., "Autoantibodies as potential biomarkers for the early detection of esophageal squamous cell carcinoma," The American Journal of Gastroenterology, vol. 109, no. 1, pp. 36-45, 2014.

[257] S. Kylarova, D. Kosek, O. Petrvalska et al., "Cysteine residues mediate high-affinity binding of thioredoxin to ASK1," The FEBS Journal, vol. 283, no. 20, pp. 3821-3838, 2016.

[258] T. M. Jeitner, M. Kalogiannis, B. F. Krasnikov, I. Gomlin, M. R. Peltier, and G. R. Moran, "Linking inflammation and Parkinson disease: hypochlorous acid generates parkinsonian poisons," Toxicological Sciences, vol. 151, no. 2, pp. 388-402, 2016.

[259] V. Nambi, "The use of myeloperoxidase as a risk marker for atherosclerosis," Current Atherosclerosis Reports, vol. 7, no. 2, pp. 127-131, 2005.

[260] J. L. Wilkinson-Berka, I. Rana, R. Armani, and A. Agrotis, "Reactive oxygen species, Nox and angiotensin II in angiogenesis: implications for retinopathy," Clinical Science, vol. 124, no. 10 , pp. 597-615, 2013. 


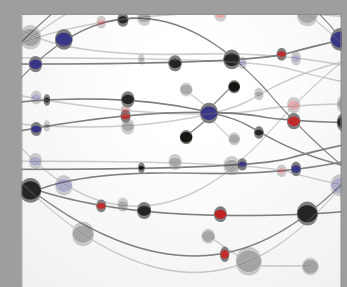

The Scientific World Journal
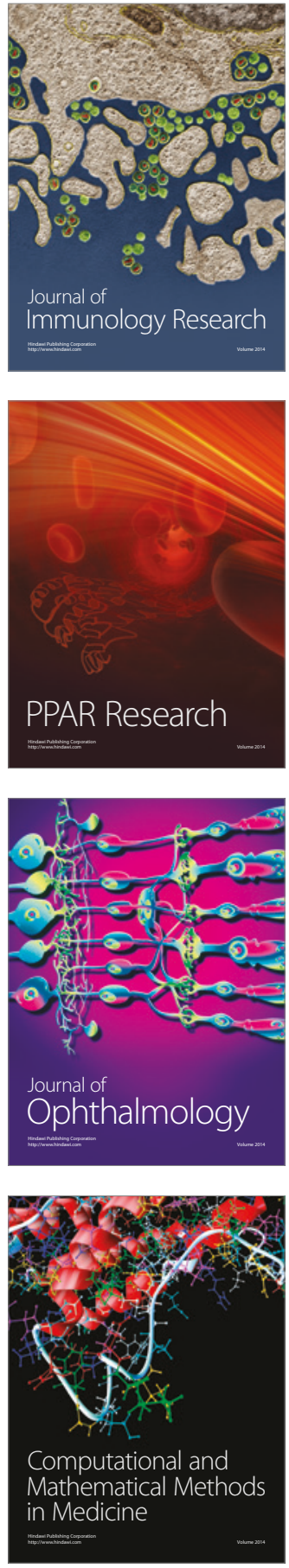

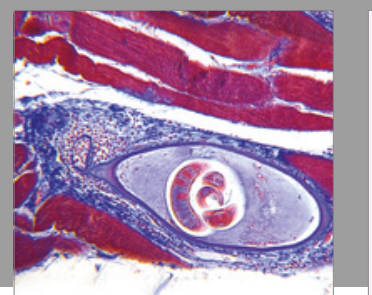

Gastroenterology Research and Practice
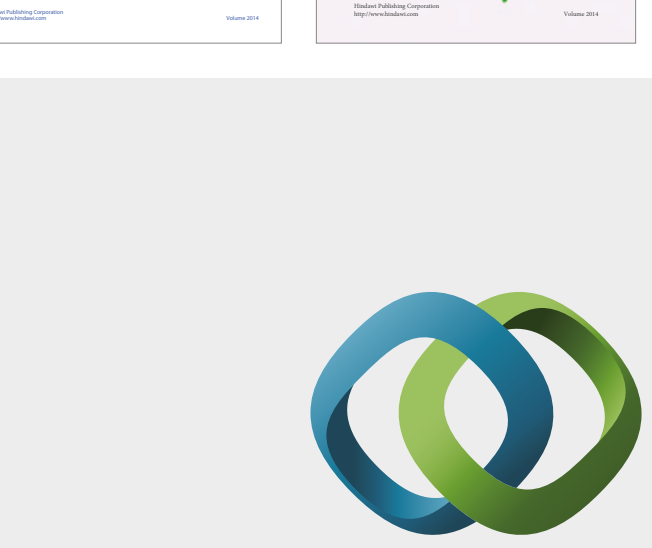

\section{Hindawi}

Submit your manuscripts at

https://www.hindawi.com
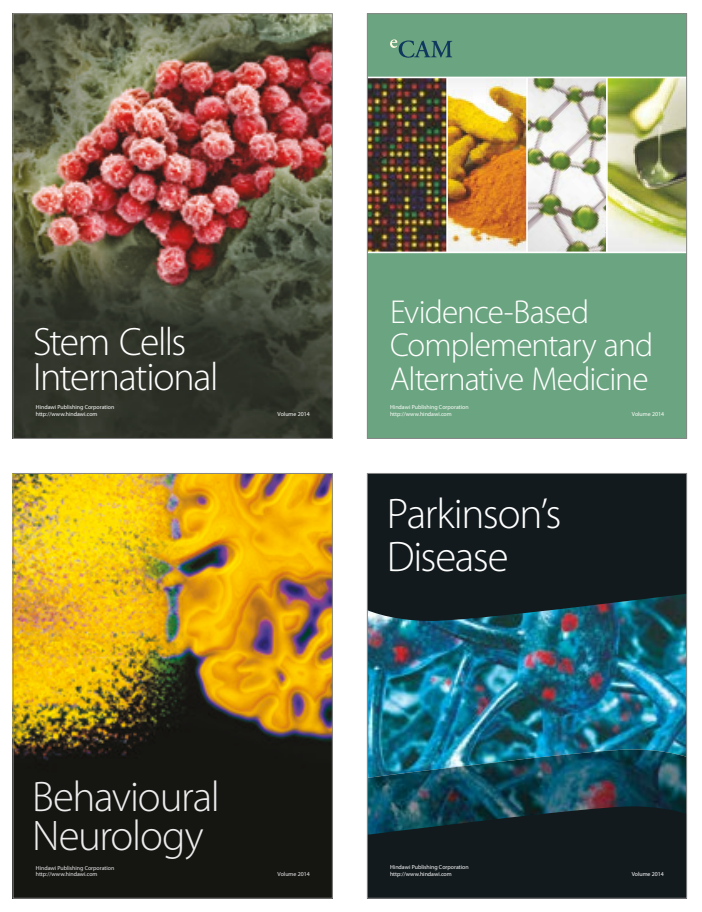
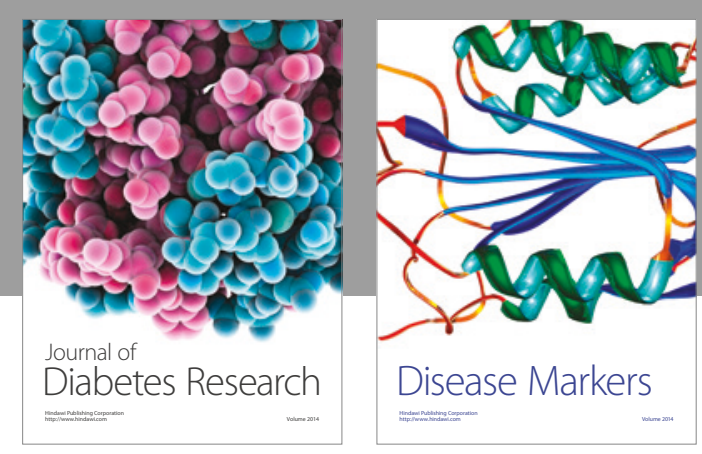

Disease Markers
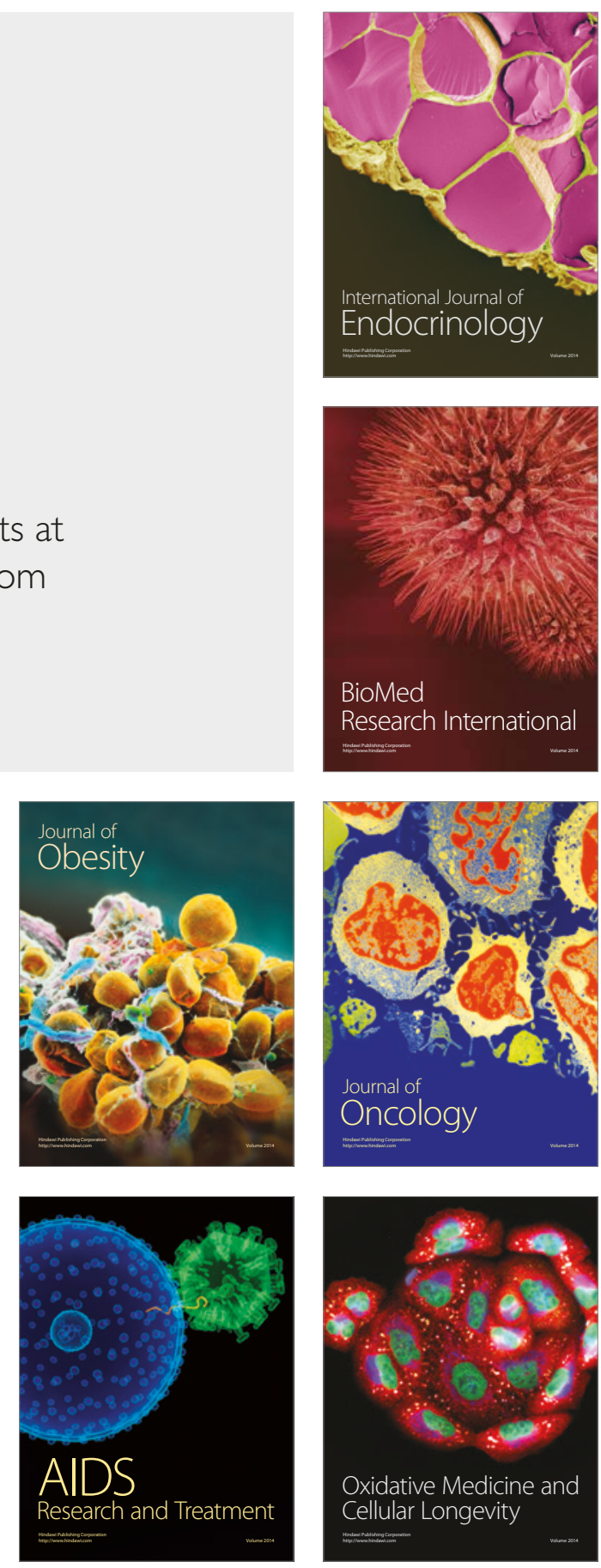